\title{
Exergy and energy analysis of a regenerative organic Rankine cycle based on flat plate solar collectors
}

\author{
Milad Ashouri ${ }^{1}$, Mohammad H. Ahmadi ${ }^{1, a}$, Michel Feidt ${ }^{2}$ and Fatemeh Razi Astaraei ${ }^{3}$ \\ 1 Renewable Energies and Environmental Department, Faculty of New Science and Technologies, University of Tehran, \\ Tehran, Iran \\ 2 Laboratoire d' Energétique et de Mécanique Théorique et Appliquée, ENSEM, 2 avenue de la Forêt de Haye, \\ 54518 Vandoeuvre, France \\ 3 Department of Renewable Energies, Faculty of New Sciences and Technologies, University of Tehran, Tehran, Iran
}

Received 23 October 2015, Accepted 14 March 2016

\begin{abstract}
In current study, a low temperature organic Rankine cycle (ORC) based on flat plate solar collectors with storage tank is considered. Due to low cost applications, water at ambient pressure is used in both the tank and collectors. Also, the cooling is done by water in ambient temperature. Energy and exergy analysis is used to evaluate the performance of the system under various conditions to find the main sources of exergy destruction and the potential to improve them. Some parameters including exergetic efficiency, thermal efficiency, exergy destruction rate, fuel depletion ratio and irreversibility ratio are investigated. Exergy efficiency and exergy destruction ratio are calculated for the overall system according to the second law of thermodynamics based on daily efficiency. Exergy analysis of each sub-system leads to the choice of the optimum physical parameters for minimum local exergy destruction ratios. Four different working fluids are considered including R245fa, R134a, pentane and toluene to evaluate the system. Results show that the solar collector, thermal storage tank and the vapor generator are the main sources of exergy destruction respectively. Also a parametric study shows that there is an optimum daily exergy efficiency based on turbine inlet temperature. Under the same load, pentane has the best performance followed by R245fa, toluene and R134a. The corresponding daily exergy efficiencies are $24.08 \%, 22.53 \%, 22.09 \%$ and $21.76 \%$.
\end{abstract}

Key words: Exergy efficiency / exergy destruction / organic Rankine cycle / flat plate collector / solar energy

\section{Introduction}

Utilizing the renewable energy resources is proved to be an alternative way to solve the energy crisis and achieve the sustainable development of human beings due to their potentials in reducing fossil fuel consumption and alleviating environmental problems. Solar energy as a promising clean renewable energy has attracted much attention particularly in recent years due to its zero pollution and broad prospects in applications. Concentrating solar power (CSP) system as an alternative effective way to utilize solar energy is a proven large-scale solar power technology with a variety of collector systems such as the parabolic trough, the solar dish, the solar tower or the Fresnel linear collector. However, most of the currently CSP plants typically include a condensing vapor cycle power block, requiring a minimum power of a few MWe

\footnotetext{
a Corresponding author:

mohammadhosein.ahmadi@gmail.com
}

and high collector temperature and large-area field. Thus, the CSP cost is not yet competitive with conventional alternatives unless subsidized. In recent years, distributed energy systems have drawn much attention due to their small-scale capacity, flexibility and high efficiency. Among power producing machines, the organic Rankine cycle has gained much attention due to its capability to work under a high range of temperatures and pressures with different working fluids. In fact, the particularity of the organic fluids is that they could be used at an evaporation temperature much lower than a conventional steam Rankine cycle, providing high efficiency [1-3]. In this study, a low temperature regenerative Rankine cycle coupled with a flat plate solar collector is investigated. A solar-powered organic Rankine cycle system with small-scale capacity compared with steam Rankine cycle has been focused on due to its low working temperature, high energy conversion efficiency and little negative impact on environment. ORC as a promising energy conversion technology 


\section{Nomenclature}

\begin{tabular}{|c|c|}
\hline$E x$ & Exergy $(\mathrm{kW})$ \\
\hline En & Energy $(\mathrm{kW})$ \\
\hline$e x$ & Specific exergy $\left({\left.\mathrm{kJ} . \mathrm{kg}^{-1}\right)}^{-1}\right.$ \\
\hline$S$ & Solar absorption $\left(\mathrm{W} \cdot \mathrm{m}^{-2}\right)$ \\
\hline$I$ & $\begin{array}{l}\text { Solar radiation }\left(\mathrm{W} \cdot \mathrm{m}^{-2}\right) \\
\text { exergy consumption }(\mathrm{kW})\end{array}$ \\
\hline$Q$ & Heat $(\mathrm{kW})$ \\
\hline$A$ & Area $\left(\mathrm{m}^{-2}\right)$ \\
\hline$c$ & Collector \\
\hline$F_{\mathrm{R}}$ & Heat removal factor of collector \\
\hline$U$ & Loss coefficient \\
\hline$T$ & Temperature $\left({ }^{\circ} \mathrm{C}\right)$ \\
\hline$\dot{m}$ & Mass flow $\left(\mathrm{kg} \cdot \mathrm{s}^{-1}\right)$ \\
\hline$C_{\mathrm{p}}$ & Heat capacity of water $\left(\mathrm{kJ} \cdot \mathrm{kg}^{-1} \cdot \mathrm{K}^{-1}\right)$ \\
\hline$D$ & Diameter $(\mathrm{m})$ \\
\hline$W$ & Width $(\mathrm{m})$ \\
\hline$C_{\mathrm{b}}$ & Bond conductance $\left(\mathrm{w} \cdot \mathrm{m}^{-1} \cdot \mathrm{k}^{-1}\right)$ \\
\hline$h$ & $\begin{array}{l}\text { Enthalpy }\left(\mathrm{kJ} \cdot \mathrm{kg}^{-1}\right) \text {; convective heat } \\
\text { transfer coefficient }\left(\mathrm{w} \cdot \mathrm{m}^{-2} \cdot \mathrm{k}^{-2}\right)\end{array}$ \\
\hline$f$ & Final state; fluid \\
\hline$k$ & Thermal conductivity $\left(\mathrm{w} \cdot \mathrm{m}^{-1} \cdot \mathrm{k}^{-1}\right)$ \\
\hline$w$ & Water; wind; work (kW) \\
\hline load & Heat load of ORC (kW) \\
\hline$H$ & Height of storage tank \\
\hline$r$ & Radius \\
\hline$V$ & Velocity $\left(\mathrm{m} . \mathrm{s}^{-1}\right)$ \\
\hline$Y_{\mathrm{D}, \mathrm{j}}^{*}$ & Irreversibility ratio \\
\hline$Y_{\mathrm{D}, \mathrm{j}}$ & Fuel depletion ratio \\
\hline \multicolumn{2}{|r|}{ Greek letters } \\
\hline$\theta$ & Incident angle to collector $\left({ }^{\circ}\right)$ \\
\hline$\varphi$ & Hour angle $\left({ }^{\circ}\right)$ \\
\hline$\delta$ & Declination angle $\left(^{\circ}\right)$ \\
\hline$\eta$ & Efficiency \\
\hline$\tau \alpha$ & $\begin{array}{l}\text { Production of transmissivity } \\
\text { and absorptivity }\end{array}$ \\
\hline \multicolumn{2}{|r|}{ Subscripts } \\
\hline $\bar{u}$ & Useful \\
\hline g & Ground \\
\hline d & Daily; diffuse \\
\hline $\mathrm{b}$ & Beam; bottom \\
\hline o & Environment; outlet \\
\hline $\mathrm{i}$ & Initial state; insulation \\
\hline $\mathrm{a}$ & Ambient \\
\hline 1 & Loss \\
\hline $\mathrm{s}$ & Storage tank; side \\
\hline $\mathrm{t}$ & Top \\
\hline $\mathrm{cw}$ & Cooling water \\
\hline
\end{tabular}

in the field of low grade heat utilization has been investigated by many researchers for decades $[4,5]$. In recent years, some researchers have paid more consideration for employing organic Rankine cycle to utilize solar energy for its abundant and sustainable resource. Li et al. [6] proposed a low temperature solar thermal electric system which consisted of compound parabolic concentra- tor (CPC) with a small concentration ratio and organic Rankine cycle with R123. Phase change materials (PCMs) were added to the system to store collected energy maintaining the stability of power output. They [7] also employed regenerative organic Rankine cycle instead of basic ORC to progress the system efficiency. Quoilin et al. [8] presented the design of a solar organic Rankine cycle installed in Lesotho. The system consisted of parabolic trough collectors, a thermal storage tank, and a smallscale ORC system using scroll expanders. With conservative hypotheses and real expander efficiency curve, the overall electrical efficiency of the system could reach $7 \%$ and $8 \%$. From the above mentioned investigations, the concentrating collectors were usually used to collect solar radiation and they were more expensive than the flat plate collector. Rayegan and Tao [9] developed a procedure to select the working fluids used in solar Rankine cycles and found that eleven working fluids had been recommended in solar ORCs that used low or medium temperature solar collectors. Wang et al. [10] conducted a comparative study of pure and zeotropic mixtures in low-temperature solar Rankine cycle and found that the zeotropic mixtures had the potential for overall system performance improvement. Except for the selection of working fluid, some researches have devoted to the sensitive analysis of key parameters and performance optimization of the solar-powered ORC. He et al. [11] conducted a simulation of a solar-powered organic Rankine cycle with parabolic trough collector using TRNSYS software. They examined the effects of several key parameters on the performance of the parabolic trough collector field based on the meteorological data of Xi'an city in China.

Delgado-Torres and Garcia-Rodriguez [12] accompanied a theoretical analysis of a low-temperature solar organic Rankine cycle. The overall efficiency of the solar ORC and its optimization with different collector types and working fluids were explored, and the influences of the regeneration process and cycle arrangement on its performance were examined. They used the solar-powered ORC to drive a reverse osmosis desalination to produce fresh water for some water shortage areas based on the previous researches [13,14]. Many other researchers have also drawn more attention to the solar organic Rankine cycle for reverse osmosis desalination, such as Kosmadakis' work [13-15] and Nafey's work [16,19] and other's [20-22]. Wang et al. [23] carried out the simulation of a solardriven regenerative organic Rankine cycle based on flatplate solar collectors using different organic working fluids. The same authors [24] carried out a parametric study and off-design performance analysis of a parabolic trough collector coupled with a regenerative ORC during a whole day. Wang et al. [25] studied a solar powered kalina cycles and evaluated the system based on average daily energy efficiency. As can be induced from the literature review, most of the works on solar ORCs have been focused on concentrating solar energy and few authors examined the performance of organic Rankine cycle coupled with flat plate collectors in different working conditions. Also, the exergy analysis has shown a more realistic 


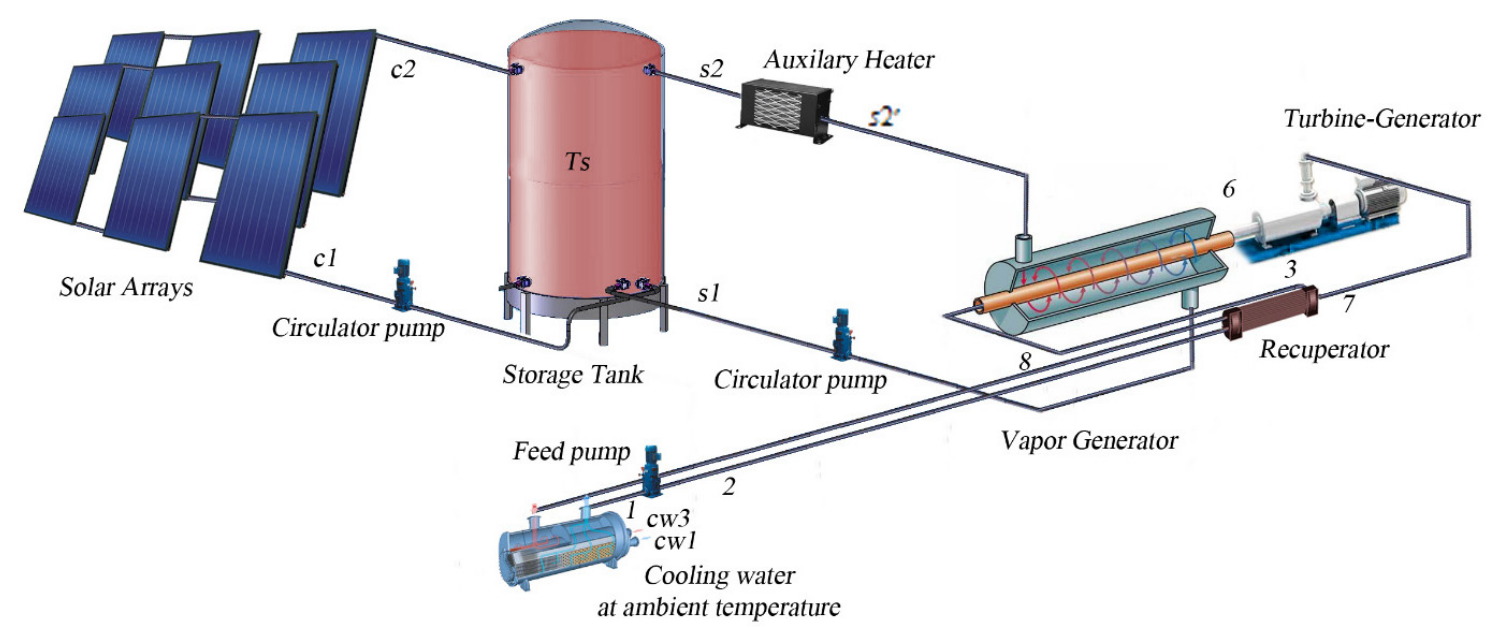

Fig. 1. Schematic of a flat plate based ORC cycle.

approach in solar applications [26]. Al-Sulaiman [27] performed a detailed exergy analysis of solar thermal power planet based on conventional Rankine cycle and a bottoming binary ORC cycle. Results showed an improvement in the performance of binary cycle compared to conventional steam Rankine cycle. ORC engines can work with a range of different working fluids made up of dry, wet and isentropic fluids [28]. In this study, we have chosen R134a, R245fa, toluen and pentane as working fluids. Among these, toluen has received less attention by authors, so we chose it to compare with other more common fluids. These working fluids are dry fluids mainly because their $T$-S diagram in superheated region has a positive slope as opposed to water, they can be used with a regenerator in the superheated region to boost thermal efficiency of the system. Also, because these fluids can work under low temperatures and pressures compared to water, they are a good choice for solar thermal applications with low grade heats. In the collector side of the cycle, a flat-plate collector has been chosen as the warm source. Also, a sensible unpressurized fully mixed storage tank collects the heat input from the collector to maintain the performance of the system during low sunshine or overcast. The existence of the thermal storage tank decreases the thermal performance of the system but is crucial to maintain the stability of the system. The following tasks are done in this study:

- Simulation and performance analysis of a solar flatplate collector coupled with an organic Rankine cycle in different working conditions and different working fluids.

- Performing energy and exergy analysis of the system to determine the energy and exergy efficiencies and also the exergy destruction rate of each component and entire system.

- Presenting a parametric study to determine the key parameters and their effect on entire system and to compare the working fluids performance under the same load.

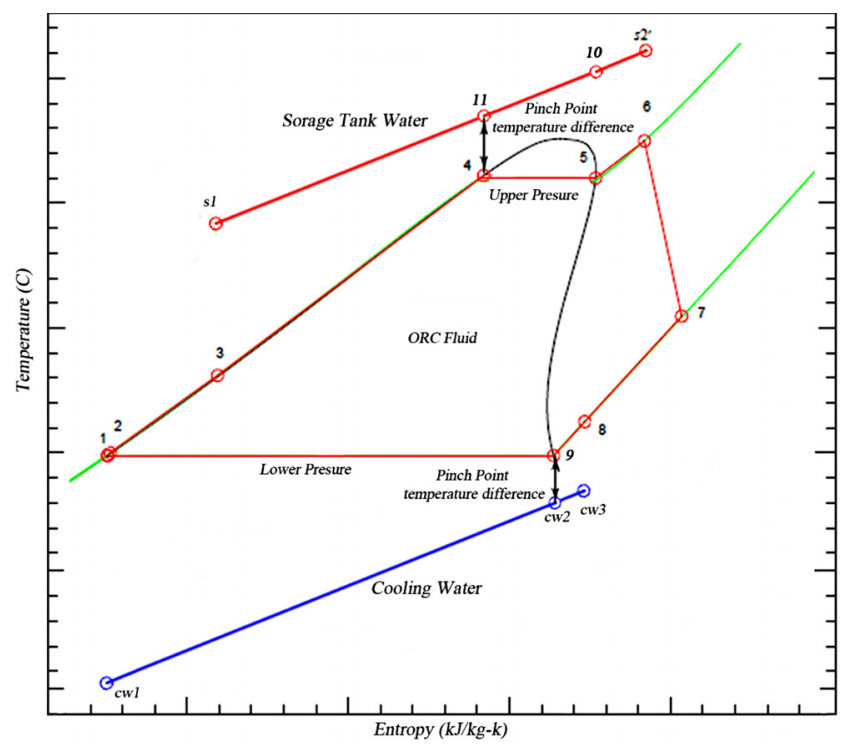

Fig. 2. Schematic of an actual regenerative organic Rankine cycle.

\section{Thermodynamic model of solar regenerative ORC system}

The schematic of the system is described in Figure 1. The system consists of a solar collector, a thermal storage tank and an ORC cycle. Solar irradiation is absorbed by the flat plate collector and the energy is stored through the storage tank to provide stable heat input to the cycle. As this is a low temperature application, water is used through the entire collector-storage system. In case of low sun shine or during night, an auxiliary heater is established to support the system. The $T$ - $S$ diagram of the ORC cycle is shown in Figure 2. As it is shown in Figure 2, the storage temperature tank falls down and the temperature of organic fluid rises in three levels including economizer, evaporator and superheater to enter the turbine. As the outlet of turbine falls in the superheated 
M. Ashouri et al.: Mechanics \& Industry 18, 217 (2017)

Table 1. Design parameters of solar ORC system.

\begin{tabular}{|c|c|c|}
\hline Parameter & Value & Unit \\
\hline Ambient pressure & 101.325 & Kpa \\
\hline Internal diameter of collector & 14 & $\mathrm{~mm}$ \\
\hline Tube spacing & 15 & $\mathrm{~mm}$ \\
\hline Plate thickness & 0.5 & $\mathrm{~mm}$ \\
\hline Heat transfer coefficient inside tubes & 300 & $\mathrm{~W} \cdot \mathrm{m}^{-2} \cdot \mathrm{K}^{-1}$ \\
\hline Thermal conductivity of glass wool & 0.04 & $\mathrm{~W}^{-1} \cdot \mathrm{m}^{-1} \mathrm{~K}^{-1}$ \\
\hline Specific heat capacity of water & 4195 & 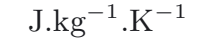 \\
\hline Specific heat capacity of steel tank & 460 & $\mathrm{~J} . \mathrm{kg}^{-1} \cdot \mathrm{K}^{-1}$ \\
\hline Tank thickness & 6 & $\mathrm{~mm}$ \\
\hline Internal diameter of storage tank & 1.7 & $\mathrm{~m}$ \\
\hline Storage tank insulation thickness & 20 & $\mathrm{~cm}$ \\
\hline Number of storage tanks & 4 & - \\
\hline Volume of storage tanks & 4.77 & $\mathrm{~m}^{3}$ \\
\hline Pinch point temperature difference & 6 & ${ }^{\circ} \mathrm{C}$ \\
\hline Pinch point temperature difference of condenser and recuperator & 5 & ${ }^{\circ} \mathrm{C}$ \\
\hline Pump \& turbine efficiency & 70 & $\%$ \\
\hline
\end{tabular}

region, a regenerator is established to recover the heat and increase the thermal efficiency of the system. The vapor in the state 8 is entered through the condenser and is cooled to saturated liquid and the cycle is repeated. The processes are described below:

1-2: Compression process in the pump

2-3: Isobaric heat absorption in the regenerator

3-4: Isobaric heat absorption in the preheater

4-5: Isobaric heat absorption in the two-phase region in evaporator

5-6: Isobaric heat absorption in the superheater

6-7: an actual expansion process through the turbine

7-8: regeneration process in the recuperator

8-1: Isobaric heat rejection in the condenser

\subsection{Flat plate collector model}

Flat plate solar collectors are widely used in industry mainly because of its simple design and relatively high efficiencies. If the temperature rise in the collector needed to be less than a hundred degrees centigrade for water at atmosphere pressure, the flat plate collectors are a good choice. Solar irradiation is absorbed by the plate and is transferred to absorber tubes and water. A 40X3 seriesparallel array of collector was established. The length and width of each collector is 2 and 1.2 respectively. It is assumed that the distance between rows is such that prevent shadowing. The total aperture is therefore $288 \mathrm{~m}^{2}$. The tilted angle of collector is $45^{\circ}$ toward the south. The array consists of 120 flat plate collectors. The space between tubes in each collector is assumed $15 \mathrm{~cm}$ and there is 8 parallel tubes per collector. Other design parameters of collector arrays and ORC can be found in Table 1. The working fluid in collectors is pure water with $C_{\mathrm{P}}$ of $4190 \mathrm{~J} \cdot \mathrm{kg}^{-1} \cdot{ }^{\circ} \mathrm{C}^{-1}$. The flow rate of water is $0.3 \mathrm{~kg} . \mathrm{s}^{-1}$. The absorbed solar radiation $S$ used for calculating useful gain of collector was calculated by equation (1) with the data available for Shiraz province in Iran [29].
The total effective heat flux entering the aperture plane is given by reference [30].

$$
\begin{aligned}
S= & I_{\mathrm{b}} R_{\mathrm{b}}(\tau \alpha)_{\mathrm{b}}+I_{\mathrm{d}}(\tau \alpha)_{\mathrm{d}}\left(\frac{1+\cos \beta}{2}\right) \\
& +\rho_{\mathrm{g}} I(\tau \alpha)_{\mathrm{g}}\left(\frac{1-\cos \beta}{2}\right)
\end{aligned}
$$

where $R_{\mathrm{b}}$ is the ratio of beam radiation on a tilted surface to that on a horizontal surface and is defined as:

$$
R_{\mathrm{b}}=\frac{\cos \theta}{\cos \theta_{z}}=\frac{\sin \delta \sin (\varphi-\beta)+\cos \delta \cos \omega \cos (\varphi-\beta)}{\sin \varphi \sin \delta+\cos \varphi \cos \delta \cos \omega} .
$$

As can be seen from Equation (1), there are terms of $I_{\mathrm{b}}$ and $I_{\mathrm{d}}$ which account for beam radiation and diffuse radiation. The global radiation was analyzed for beam and diffuse components, obtained based in Equation (2):

$$
K_{\mathrm{T}}=\frac{I}{I_{\mathrm{O}}}
$$

where $K_{\mathrm{T}}$ is the hourly clearness index. The diffuse part of radiation is defined as:

$$
\frac{I_{\mathrm{d}}}{I}=\left\{\begin{array}{l}
1.0-0.09 K_{\mathrm{T}}\left(K_{\mathrm{T}} \leqslant 0.22\right) \\
0.9511-0.1604 K_{\mathrm{T}}+4.388 K_{\mathrm{T}}^{2}\left(0.22 \leqslant K_{\mathrm{T}} \leqslant 0.80\right) \\
0.165\left(0.8 \leqslant K_{\mathrm{T}}\right)
\end{array}\right\} .
$$

The results are shown in Figure 5 for a typical day of May. The useful heat gain rate, namely the rate of heat transfer to working fluid, is given by:

$$
Q_{\mathrm{u}}=A_{\mathrm{c}} F_{\mathrm{R}}\left[S-U_{\mathrm{L}}\left(T_{\mathrm{i}}-T_{\mathrm{a}}\right)\right]
$$

where $F_{\mathrm{R}}$ is the heat removal factor and is defined by:

$$
F_{\mathrm{R}}=\frac{\dot{m} C_{\mathrm{p}}}{A_{\mathrm{c}} U_{\mathrm{L}}}\left[1-\exp \left(-\frac{A_{\mathrm{c}} U_{\mathrm{L}} F^{\prime}}{\dot{m} C_{\mathrm{p}}}\right)\right]
$$


where

$$
F^{\prime}=\frac{1 / U_{\mathrm{L}}}{W\left[\frac{1}{U_{\mathrm{L}}(D+(W-D) F)}+\frac{1}{C_{\mathrm{b}}}+\frac{1}{\pi D_{\mathrm{i}} h_{\mathrm{fi}}}\right]} .
$$

In performance analysis of solar collectors heat losses are very important. The term for these losses is loss coefficient $U_{\mathrm{L}}$ and is the sum of three loss coefficients:

$$
\begin{aligned}
& U_{\mathrm{L}}=U_{\mathrm{b}}+U_{\mathrm{t}}+U_{\mathrm{s}} \\
& U_{\mathrm{b}}=\frac{k_{\mathrm{i}}}{\delta_{\mathrm{b}}}
\end{aligned}
$$

where $U_{\mathrm{b}}$ is the bottom loss coefficient and is defined as the ratio of thermal conductivity of the insulation $k_{\mathrm{i}}$ to the insulation thickness $\delta_{\mathrm{b}}$. If $a, b$ and $c$ are the dimensions of the plate and $\delta_{\mathrm{i}}$ is the insulation thickness, then the side loss coefficient would be:

$$
U_{\mathrm{s}}=\frac{2 k_{\mathrm{i}}(a+b) c}{\delta_{\mathrm{i}} a b}
$$

$U_{\mathrm{t}}$ is the top loss coefficient and has been empirically proposed by Klein [30].

$$
\begin{aligned}
U_{\mathrm{t}}= & {\left[\frac{N}{\frac{C}{T_{\mathrm{pm}}}\left[\frac{\left(T_{\mathrm{pm}}-T_{\mathrm{a}}\right)}{(N+f)}\right]^{e}}+\frac{1}{h_{\mathrm{w}}}\right]^{-1} } \\
& +\frac{\sigma\left(T_{\mathrm{pm}}+T_{\mathrm{a}}\right)\left(T_{\mathrm{pm}}^{2}+T_{\mathrm{a}}^{2}\right)}{\frac{1}{\varepsilon_{\mathrm{p}}+0.00591 N h_{\mathrm{w}}}+\frac{2 N+f-1+0.133 \varepsilon_{\mathrm{p}}}{\varepsilon_{\mathrm{g}}}-N}
\end{aligned}
$$

where the parameter $N=2$ accounts for the number of glass covers which improves the collector performance according to Duffie and Beckman [30]. Also $f, C$ and $e$ are as follow:

$$
\begin{aligned}
f & =\left(1+0.089 h_{\mathrm{w}}-0.1166 h_{\mathrm{w}} \varepsilon_{\mathrm{p}}\right)(1+0.07866 N) \\
C & =520\left(1-0.000051 \beta^{2}\right) \\
e & =0.430\left(1-100 / T_{\mathrm{pm}}\right)
\end{aligned}
$$

where $h_{\mathrm{w}}$ is the wind heat transfer coefficient defined as:

$$
h_{\mathrm{w}}=\frac{K N u}{L}
$$

where

$$
L=\frac{4 A_{\mathrm{c}}}{p_{\mathrm{c}}} .
$$

Also the mean fluid temperature and plate mean temperature are obtained using this equations:

$$
\begin{aligned}
& T_{\mathrm{fm}}=T_{\mathrm{fi}}+\frac{Q_{\mathrm{u}} / A_{\mathrm{c}}}{F_{\mathrm{R}} U_{\mathrm{L}}}\left(1-F^{\prime \prime}\right) \\
& T_{\mathrm{pm}}=T_{\mathrm{fi}}+\frac{Q_{\mathrm{u}} / A_{\mathrm{c}}}{F_{\mathrm{R}} U_{\mathrm{L}}}\left(1-F_{\mathrm{R}}\right) .
\end{aligned}
$$

The thermal efficiency of collector array is given by:

$$
\eta_{\mathrm{col}}=\frac{Q_{\mathrm{u}}}{A_{\mathrm{c}, \mathrm{t}} I} \text {. }
$$

The procedure for finding the useful gain and output temperature is shown in Figure 3.

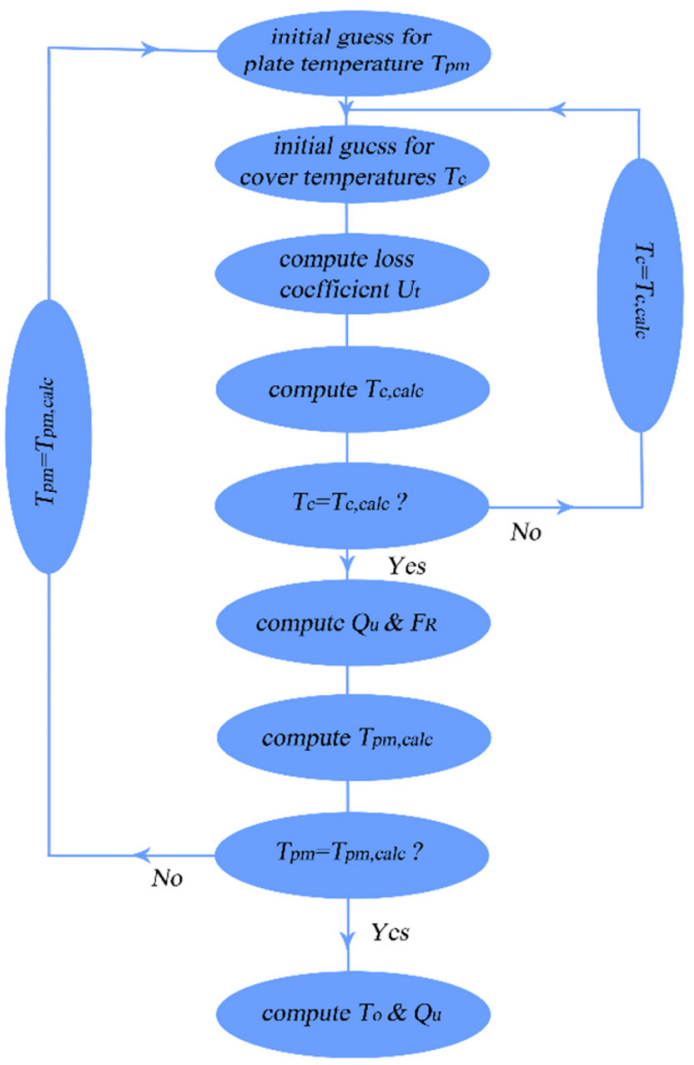

Fig. 3. Procedure for finding output temperature and useful gains of collector.

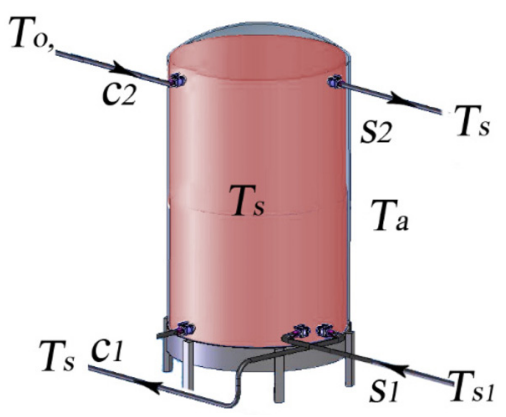

Fig. 4. Schematic of a fully mixed storage tank.

\subsection{Thermal storage tank model}

A fully mixed sensible storage tank is assumed in the model. Water is used in the tank due to low temperature and low cost applications. The water exiting the tank is assumed to be mixed completely with water entering the tank as shown in Figure 4. Therefore the tank temperature is constant during each one hour period and is calculated by reference [31].

$$
\left[\left(\rho V C_{\mathrm{p}}\right)_{\mathrm{w}}+\left(\rho V C_{\mathrm{p}}\right)_{\mathrm{t}}\right] \frac{\mathrm{d} T_{S}}{\mathrm{~d} t}=Q_{\mathrm{u}}-Q_{\text {load }}-Q_{\mathrm{l}}
$$

where $t$ and $w$ account for tank and water. 
M. Ashouri et al.: Mechanics \& Industry 18, 217 (2017)

Table 2. Working fluids and their thermophysical properties and working conditions.

\begin{tabular}{ccccccc}
\hline $\begin{array}{c}\text { Working } \\
\text { Fluids }\end{array}$ & $\begin{array}{c}\text { Critical } \\
\text { Pressure }(\mathrm{kpa})\end{array}$ & $\begin{array}{c}\text { Critical } \\
\text { Temperature }\left({ }^{\circ} \mathrm{C}\right)\end{array}$ & $\begin{array}{c}\text { Molecular } \\
\text { Weight }(\mathrm{g} / \mathrm{mol})\end{array}$ & $\begin{array}{c}\text { Thermal } \\
\text { efficiency }(\%)\end{array}$ & $\begin{array}{c}\text { Lower operating } \\
\text { pressure }(\mathrm{kpa})\end{array}$ & $\begin{array}{c}\text { Upper operating } \\
\text { pressure }(\mathrm{kpa})\end{array}$ \\
\hline R134a & 4059.3 & 101.06 & 102.03 & 4.25 & 770.2 & 1310 \\
R245fa & 3651 & 154.01 & 134.05 & 4.39 & 177 & 340 \\
Toluene & 4126.3 & 318.6 & 92.138 & 4.10 & 4.89 & 11.77 \\
pentane & 3370 & 196.55 & 72.149 & 4.61 & 81.99 & 159.25 \\
\hline
\end{tabular}

The useful gain, load of the system and heat loss are given as:

$$
\begin{aligned}
Q_{\mathrm{u}} & =\dot{m}_{\mathrm{c}} C_{\mathrm{p}}\left(T_{\mathrm{o}}-T_{\mathrm{i}}\right) \\
Q_{\text {load }} & =\dot{m}_{\mathrm{st}} C_{\mathrm{p}}\left(T_{\mathrm{s}}-T_{\mathrm{s} 1}\right) \\
Q_{\mathrm{l}} & =(U A)_{\mathrm{t}}\left(T_{\mathrm{s}}-T_{\mathrm{a}}\right),
\end{aligned}
$$

where $(U A)_{\mathrm{t}}$ is the product of the overall heat transfer coefficient and surface area and for an insulated tank is defined as:

$$
(U A)_{\mathrm{t}}=\frac{k_{\mathrm{i}}}{r_{1}} /\left(\ln \left(\frac{r_{2}}{r_{2}}\right)\right)\left(2 \pi r_{1} H\right)+\frac{k_{\mathrm{i}}}{\delta_{\mathrm{i}}}\left(2 \pi r_{1}^{2}\right) .
$$

The energy balance for the thermal storage is given by reference [32]

$$
\begin{array}{r}
E n_{\mathrm{c} 2}-E n_{\mathrm{c} 1}-\left[E n_{\mathrm{s} 2}-E n_{\mathrm{s} 1}+Q_{1}\right]=\Delta E n_{\mathrm{s}} \\
\Delta E n_{\mathrm{s}}=E n_{f}-E n_{\mathrm{i}} .
\end{array}
$$

\subsection{Organic Rankine cycle mathematical model}

Solar thermal energy can be converted to electricity by various methods including photovoltaic and thermodynamic cycles [33]. Photovoltaic applications are not still commercially proven because of high costs and low efficiencies. Also, with various thermodynamic power cycles including Brayton, Rankine and Stirling engines, it is possible to convert low grade heat thermal energy to electricity using a thermal storage system more efficiently and cost effectively. The ORC system in this study is designed with working fluids operating in low pressures and temperatures. The first reason is that the storage tank is a fully mixed unpressurized tank so the water temperature cannot exceed $100{ }^{\circ} \mathrm{C}$ because of evaporation. Also, as the condenser uses water at ambient temperature and pressure, the lower pressure of the ORC system cannot be lowered too much because of pinch point limitation in the condenser. These measures lead to a low cost of system in compromising the low output power and efficiency. The selected working fluids are shown in Table 2. The equations used in the model are as follows. The equations were developed in MATLAB software and the thermophysical properties of working fluids were obtained by National Institute of Standards and Technology [34].
The energy balance of each component in the system is defined as:

$$
\begin{aligned}
\dot{W}_{\mathrm{cv}}= & \sum_{j} \dot{Q}_{j}+\sum_{\text {in }} \dot{m}_{\text {in }}\left(h_{\text {in }}+\frac{V_{\text {in }}^{2}}{2}+g z_{\text {in }}\right) \\
& -\sum_{\text {out }} \dot{m}_{\text {out }}\left(h_{\text {out }}+\frac{V_{\text {out }}^{2}}{2}+g z_{\text {ou }}\right) .
\end{aligned}
$$

Pump feed in the ORC cycle:

$$
\eta_{\text {pump }}=\frac{W_{\text {pump }, \mathrm{s}}}{W_{\text {pump }}}=\frac{\dot{m}_{\mathrm{ORC}}\left(h_{2 s}-h_{1}\right)}{\dot{m}_{\mathrm{ORC}}\left(h_{2}-h_{1}\right)} .
$$

Vapor Generator consists of preheater, evaporator and superheater.

Preheater:

$$
\dot{m}_{\mathrm{ORC}}\left(h_{4}-h_{3}\right)=\dot{m}_{\mathrm{w}} C_{\mathrm{p}}\left(T_{11}-T_{\mathrm{s} 1}\right) .
$$

Evaporator:

$$
\dot{m}_{\mathrm{ORC}}\left(h_{5}-h_{4}\right)=\dot{m}_{\mathrm{w}} C_{\mathrm{p}}\left(T_{10}-T_{11}\right) .
$$

Superheater:

$$
\dot{m}_{\mathrm{ORC}}\left(h_{6}-h_{5}\right)=\dot{m}_{\mathrm{w}} C_{\mathrm{p}}\left(T_{\mathrm{s} 2^{\prime}}-T_{10}\right) .
$$

The overall input heat to the system is:

$$
Q_{1}=\dot{m}_{\mathrm{ORC}}\left(h_{6}-h_{3}\right) \text {. }
$$

The isentropic efficiency of the turbine is defined as:

$$
\eta_{\text {turbine }}=\frac{h_{6}-h_{7}}{h_{6}-h_{7 s}} .
$$

The condenser model consists of two regions, single phase and two phases:

- Single phase:

$$
\dot{m}_{\mathrm{ORC}}\left(h_{8}-h_{9}\right)=\dot{m}_{\mathrm{cw}} C_{\mathrm{p}}\left(T_{\mathrm{cw} 3}-T_{\mathrm{cw} 2}\right) .
$$

- Two phases:

$$
\dot{m}_{\mathrm{ORC}}\left(h_{9}-h_{1}\right)=\dot{m}_{\mathrm{cw}} C_{\mathrm{p}}\left(T_{\mathrm{cw} 2}-T_{\mathrm{cw} 1}\right) .
$$

The water enters the condenser at ambient temperature and leaves the condenser after rising temperature. Then, it can be collected at a well to transfer its heat to ambient and return to the system. 
The net power out of the system is defined as:

$$
W_{\text {net }}=\dot{m}_{\mathrm{ORC}}\left(h_{6}-h_{7}-h_{2}+h_{1}\right) \text {. }
$$

Also, the thermal efficiency of the ORC engine is defined as:

$$
\eta_{\mathrm{ORC}}=\frac{W_{\text {net }}}{Q_{1}}
$$

Due to the transient behavior of the solar system and also the existence of storage tank, an overall daily thermal efficiency was used for performance evaluation of the system which was introduced by Wang et al. [23].

$$
\eta_{\mathrm{en}, \mathrm{d}}=\frac{\operatorname{sum}\left(W_{\text {net }}\right)}{\operatorname{sum}\left(Q_{\mathrm{u}}\right)}
$$

where sum implies the summation of energies during the investigated periods. day:

Also Solar Fraction is defined as follow for a whole

$$
S F=\frac{Q_{1}-Q_{\mathrm{aux}}}{Q_{1}}
$$

\section{Exergy analysis}

Exergy analysis completes energy analysis and enhances many problems facing conventional energy based evaluation methods. The exergy balance in the system is defined as:

$$
\begin{aligned}
\dot{W}_{\mathrm{cv}}= & \sum_{j} \dot{Q}_{j}\left(1-\frac{T_{0}}{T_{j}}\right)+\sum_{\text {in }} \dot{m}_{\mathrm{in}} e x_{\mathrm{in}} \\
& -\sum_{\text {out }} \dot{m}_{\mathrm{out}} e x_{\mathrm{out}}-\dot{E} x_{\mathrm{d}}
\end{aligned}
$$

where $\dot{E} x_{\mathrm{d}}, e x$ and $T$ are the exergy destruction, exergy per unit mass flow and temperature respectively. The subscript $c v$ implies the control volume for each component and $j$ is referred to the state. Also, 0 is the referenced environment and in and out are the inlet and exit states. The exergy per unit mass flow can be defined as:

$$
\begin{aligned}
e x=e x^{p h}= & \left(h-h_{0}\right)-T_{0}\left(s-s_{0}\right)+\left(\frac{V^{2}-V_{0}^{2}}{2}\right) \\
& +g\left(z-z_{0}\right) .
\end{aligned}
$$

Because there is not any chemical change in the working fluids throughout the system, the chemical exergy is neglected.

For the flat plate collector, the sun's input exergy to the system can be defined as [35]:

$$
E x_{\mathrm{sun}, \text { in }}=A_{\mathrm{c}, \mathrm{t}} G_{\mathrm{b}}\left(1+\frac{1}{3}\left(\frac{T_{0}}{T_{\mathrm{sun}}}\right)^{4}-\frac{4}{3}\left(\frac{T_{0}}{T_{\mathrm{sun}}}\right)\right) \text {. }
$$

The exergy balance for the storage tank is given by:

$$
E x_{\mathrm{c} 2}-E x_{\mathrm{c} 1}-\left[E x_{\mathrm{s} 2}-E x_{\mathrm{s} 1}+X_{1}\right]-I=\Delta E x_{\mathrm{st}}
$$

where $X_{1}$ and $I$ are the exergy loss and exergy consumption in the tank.

$$
\begin{aligned}
X_{\mathrm{l}} & =\left(1-\frac{T_{\mathrm{o}}}{T_{\mathrm{s}}}\right) Q_{\mathrm{l}} \\
\Delta E x_{\mathrm{s}} & =E x_{f}-E x_{\mathrm{i}}
\end{aligned}
$$

$f$ and $i$ denote the final and initial states.

The exergetic efficiency of collector is defined as:

$$
\eta_{\mathrm{ex}, \mathrm{col}}=\frac{E x_{\mathrm{c} 2}-E x_{\mathrm{c} 1}}{E x_{\mathrm{sun}, \mathrm{in}}} .
$$

The ORC exergetic efficiency is defined based on the input exergy to the vapor generator.

$$
\eta_{\mathrm{ex}, \mathrm{ORC}}=\frac{W_{\mathrm{net}}}{E x_{\mathrm{s} 2^{\prime}}-E x_{\mathrm{s} 1}} .
$$

In solar applications, heat source shows a transient behavior and we should use a thermal storage system in order to store heat during low demand and use it during overcast, nights or high demand. Therefore, it is not a good idea to use instant efficiency as it does not show the performance of the system during night or low demand. Instead, we used an average daily exergy efficiency as follows:

$$
\eta_{\mathrm{ex}, \mathrm{d}}=\frac{\operatorname{sum}\left(W_{\mathrm{net}}\right)}{\operatorname{sum}\left(E x_{\mathrm{u}, \mathrm{in}}\right)}
$$

where $E x_{\mathrm{u}, \text { in }}$ is the useful input exergy from the collector and the auxiliary heater.

The irreversibility ratio and exergetic fuel depletion ratio are defined as reference [36]:

$$
\begin{aligned}
Y_{\mathrm{D}, \mathrm{j}}^{*} & =\frac{E x_{\mathrm{d}, \mathrm{j}}}{E x_{\mathrm{D}, \text { total }}} \\
Y_{\mathrm{D}, \mathrm{j}} & =\frac{E x_{\mathrm{d}, \mathrm{j}}}{E x_{\text {total }, \mathrm{in}}}
\end{aligned}
$$

where irreversibility ratio is the ratio of destructed exergy in the component to the total destructed exergy. Also, the fuel depletion ratio shows the portion of total inlet exergy which is destructed in a component.

\subsection{Exergy destructions and exergetic efficiencies}

In the present work, the exergy of each flow is evaluated and the exergy changes in the components are determined. The exergy destruction rate and the exergy efficiency for each component and for the overall system (depicted in Fig. 1) are shown in Table 3. The main source of exergy destruction (or irreversibility) in the overall system is the collector series. This is due to the fact that flat plate collectors do not concentrate the sun's rays to bring up the temperature and most of the input exergy from 
M. Ashouri et al.: Mechanics \& Industry 18, 217 (2017)

Table 3. Expressions for exergy destruction rate and exergy efficiency for solar powered ORC.

\begin{tabular}{|c|c|c|}
\hline$j$ & $E x_{\mathrm{d}, \mathrm{j}}$ & $\eta_{\mathrm{ex}, \mathrm{j}}$ \\
\hline Flat plate collectors & $E x_{\mathrm{d}, \mathrm{col}}=E x_{\mathrm{sun}, \mathrm{in}}+E x_{\mathrm{c} 1}-E x_{\mathrm{c} 2}$ & $\eta_{\mathrm{ex}, \mathrm{col}}=\frac{E x_{\mathrm{c} 2}-E x_{\mathrm{c} 1}}{E x_{\mathrm{sun}, \mathrm{in}}}$ \\
\hline Storage tank & $E x_{\text {loss }, \tan \mathrm{k}}=X_{1}+I$ & $\eta_{\mathrm{ex}, \tan \mathrm{k}}=1-\frac{}{E x_{\mathrm{c} 2}-E x_{\mathrm{c} 1}}$ \\
\hline Auxiliary heater & $E x_{\mathrm{d}, \mathrm{aux}}=E x_{\mathrm{s} 2}-E x_{\mathrm{s} 2^{\prime}}+Q_{\mathrm{aux}}\left(1-\frac{T_{0}}{T_{\mathrm{aux}}}\right)$ & $\begin{aligned} \eta_{\mathrm{ex}, \tan \mathrm{k}}= & 1-\frac{E x_{\mathrm{d}, \mathrm{aux}}}{E x_{\mathrm{in}, \mathrm{aux}}} \\
& E x_{6}-E x_{3}\end{aligned}$ \\
\hline Vapor generator & $E x_{\mathrm{d}, \mathrm{VG}}=E x_{\mathrm{s} 2^{\prime}}-E x_{\mathrm{s} 1}+E x_{3}-E x_{6}$ & $\eta_{\mathrm{ex}, \mathrm{VG}}=\frac{E x_{6}-E x_{3}}{E x_{\mathrm{s} 2^{\prime}}-E x_{\mathrm{s} 1}}$ \\
\hline Turbine & $E x_{\mathrm{d}, \mathrm{T}}=E x_{6}-E x_{7}+W_{\mathrm{T}}$ & $\eta_{\mathrm{ex}, \mathrm{T}}=\frac{W_{\mathrm{T}}}{E x_{6}-E x_{7}}$ \\
\hline Recuperator & $E x_{\mathrm{d}, \mathrm{Rec}}=E x_{7}-E x_{8}+E x_{2}-E x_{3}$ & $\eta_{\mathrm{ex}, \mathrm{Rec}}=\frac{E x_{7}-E x_{8}}{E x_{3}-E x_{2}}$ \\
\hline Condenser & $E x_{\mathrm{d}, \mathrm{Cond}}=E x_{\mathrm{cw} 1}-E x_{\mathrm{cw} 3}+E x_{8}-E x_{1}$ & $\eta_{\mathrm{ex}, \text { Cond }}=1-\frac{E x_{\mathrm{d}, \mathrm{Cond}}}{E x_{\mathrm{in}, \text { Cond }}}$ \\
\hline Feed pump & $E x_{\mathrm{d}, \mathrm{pump}}=E x_{1}-E x_{2}+W_{\mathrm{p}}$ & $\eta_{\mathrm{ex}, \mathrm{Pump}}=\frac{E x_{2}-E x_{1}}{W_{\mathrm{p}}}$ \\
\hline
\end{tabular}

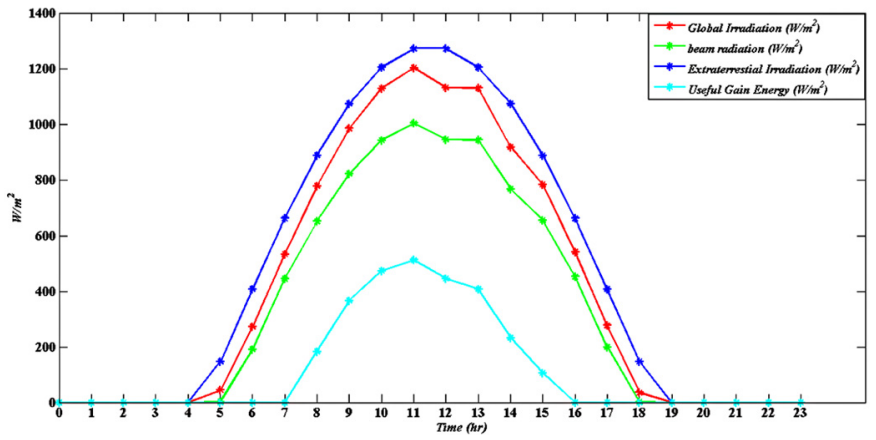

Fig. 5. Irradiation data for an useful gain of collector in a typical day (May 15th).

the sun is lost. The second important source of exergy destruction in the system is the vapor generator which acts as the boiler for the ORC system and is mainly due to the heat transfer across large temperature differences and thermal losses in the flow path [37]. Also exergy destruction in the condenser heat exchanger is due to the temperature differences between the cooling water and hot outlet fluid. The condenser exergy destruction could be lowered with using heat exchanger with lower pinch point temperature difference. It is generally observed that for processes involving heat transfer across large temperature differences, the exergy destruction will be high [38]. This is shown in Figure 18. In the mid-day the temperature difference in the heat exchanger boiler rises and the destruction in these periods is higher.

\section{Results and discussion}

\subsection{Collector and storage system}

The irradiation data for a given month in Shiraz province (latitude: $35.73 \mathrm{~N}$ ) is given in Figure 5 . As it is shown in the figure, the extraterrestrial irradiation is always more than global radiation and is calculated

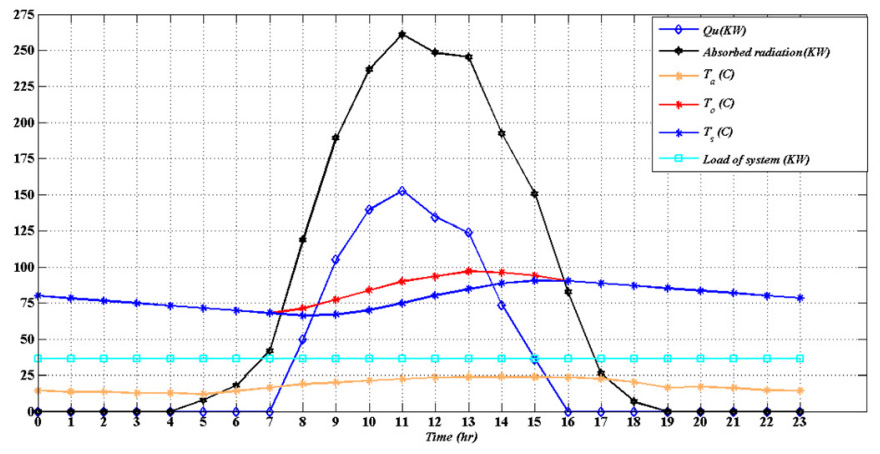

Fig. 6. System performance during a typical day under constant load of ORC.

by Duffie and Beckman [30]. Also, beam radiation is the portion of the global radiation that directly heats the collector. The collectors start to gain energy at about $7 \mathrm{AM}$ and reaches its peak at about 11 AM. Although their radiation is available at $5 \mathrm{AM}$ to $7 \mathrm{Am}$, the collectors do not gain useful energy because the thermal losses prevent the collectors to absorb useful energy and thus no useful heat transfer occurs in these periods.

Figure 6 shows the variation of tank temperature during a day under constant load of ORC system. This will lead to a constant output power during the day. As can be seen in the figure, the output temperature of collector exceeds the tank temperature during the day and brings useful heat to the tank to be stored and used at night. Between 9:00 to 15:00, input heat to the storage tank is higher than output heat and the tank temperature rises. In other times the storage tank releases heat and temperature falls down. During the night, the pump stops circulating the water to collector to prevent heat loss. Whenever the tank temperature falls below the required temperature for ORC system, the auxiliary heater brings the temperature up to meet the demand. This will help to provide stable output power throughout the day. 


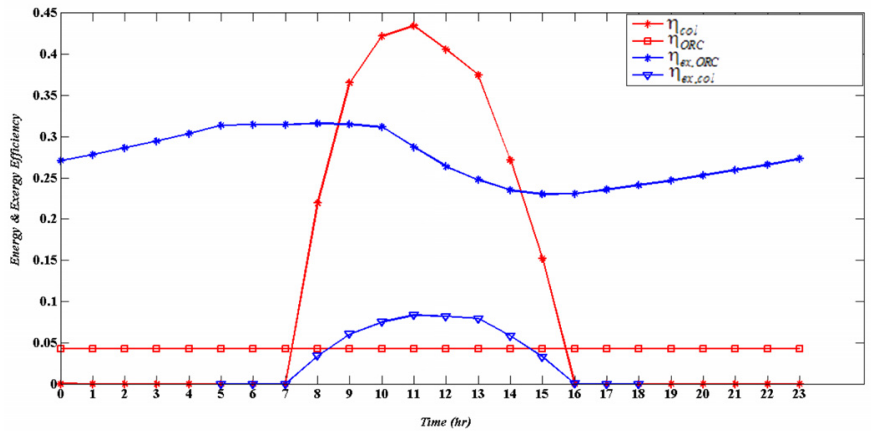

Fig. 7. Variation of energetic and exergetic efficiencies of collector and ORC during a day.

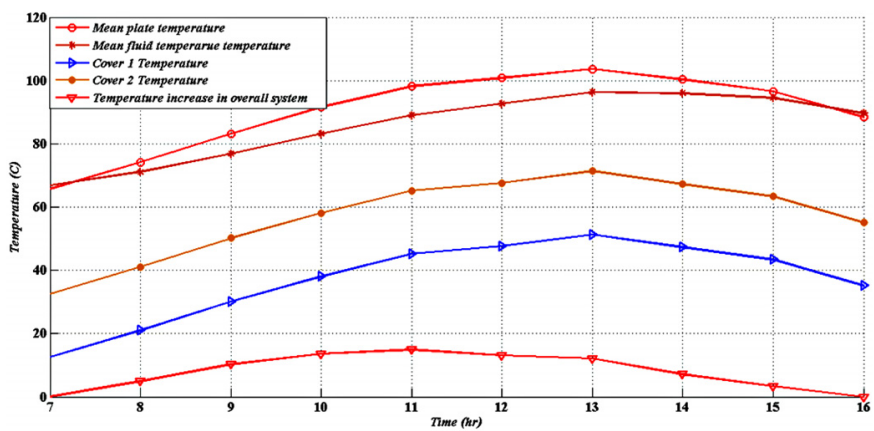

Fig. 8. Variation of temperature in various components of the collector.

Figure 7 shows the instant efficiencies of the ORC engine and the collector arrays based on equations (45), to (46), (36) and (19). The collector reaches its peak efficiency during the day and falls thereafter. As can be seen in Figures 5 and 6, both $Q_{\mathrm{u}}$ and absorbed radiation reach their peak during the day but the effect of $Q_{\mathrm{u}}$ is higher and leads to better collector performance and higher efficiency. Also, the ORC instant efficiency is constant during the day and is around 4 percent due to constant load throughout the day. This efficiency could be improved by lowering the lower pressure of the cycle but this will lead to cooling water to be at lower temperature of ambient, which is not desirable for a low cost application. The exergy efficiencies are also shown in the Figure 7. The exergy efficiency of the collector has the same trend as thermal efficiency. The exergy efficiency of the ORC cycle is increased till $10 \mathrm{AM}$ and start to fall as the storage tank temperature increases, this is because the pinch temperature difference in vapor generator starts to increase and thermal losses increase. Also, the ambient temperature rises (see Fig. 6) and is effective in decreasing the exergy efficiency of the system. In order to investigate the performance of flat plate collector, Figure 8 shows the temperature of various components in a collector unit. Mean plate temperature is always higher than fluid temperature and reaches its peak at 13:00. The maximum overall temperature increase in the collector occurs at 11:00.

Figure 9 shows the variation of wind speed during the day over one unit of collector and its corresponding wind heat transfer coefficient which is very dependent on wind

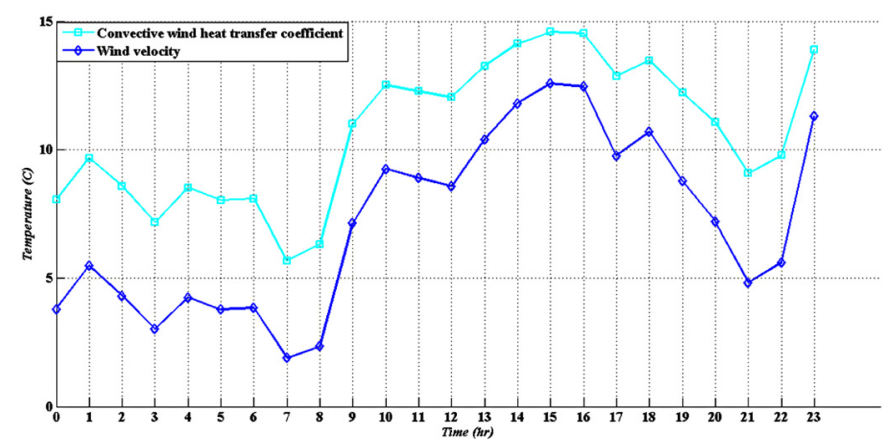

Fig. 9. Variation of wind speed and corresponding wind heat transfer coefficient during the day.

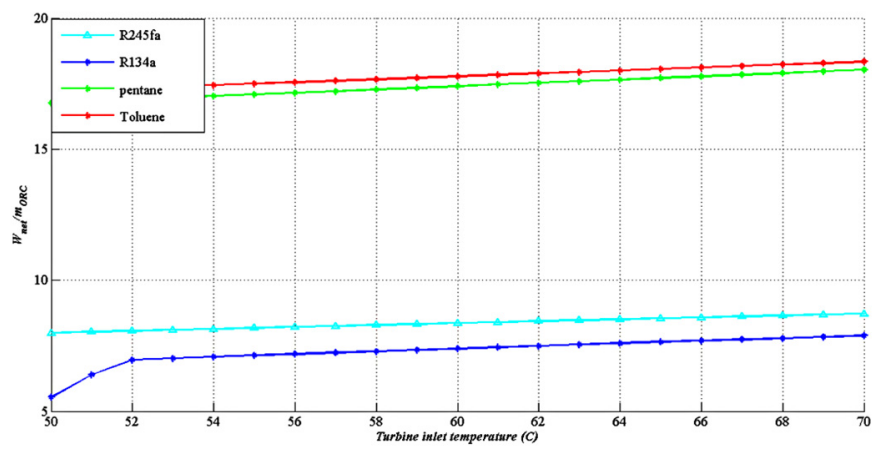

Fig. 10. Effect of turbine inlet temperature on the specific work of the ORC.

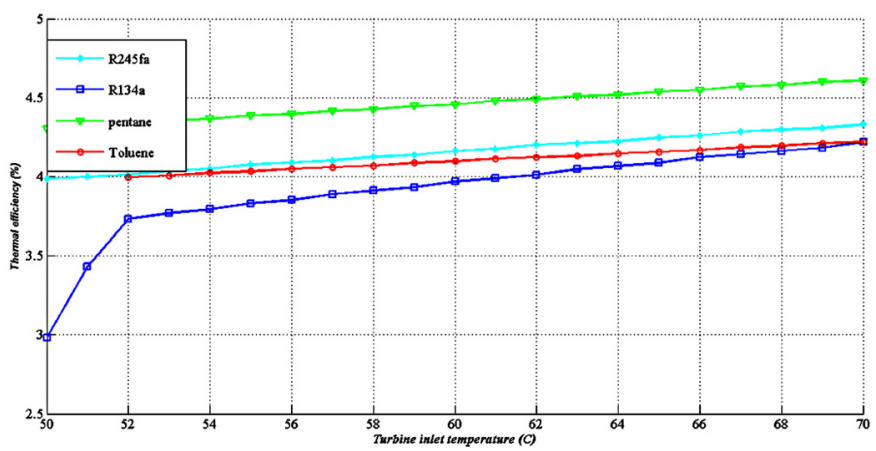

Fig. 11. Effect of turbine inlet temperature on the thermal efficiency of the ORC.

speed and affects the performance of collector. As the wind speed is higher between 7:00 to 16:00, which solar absorption occurs, the wind heat transfer has its peak during these hours.

\subsection{ORC system}

Figures 10-15 show the effect of key parameters on the performance of ORC. According to Figures 10 and 11, increasing the turbine inlet temperature will increase the output work and causes the thermal efficiency to rise slightly. Also, increasing the turbine inlet pressure has a positive effect on the output work and thermal efficiency as can be seen in Figures 12 and 13 but the increase in thermal efficiency is slight. Thus, for safe and low cost applications, in Table 2 upper pressures are selected for base case. 


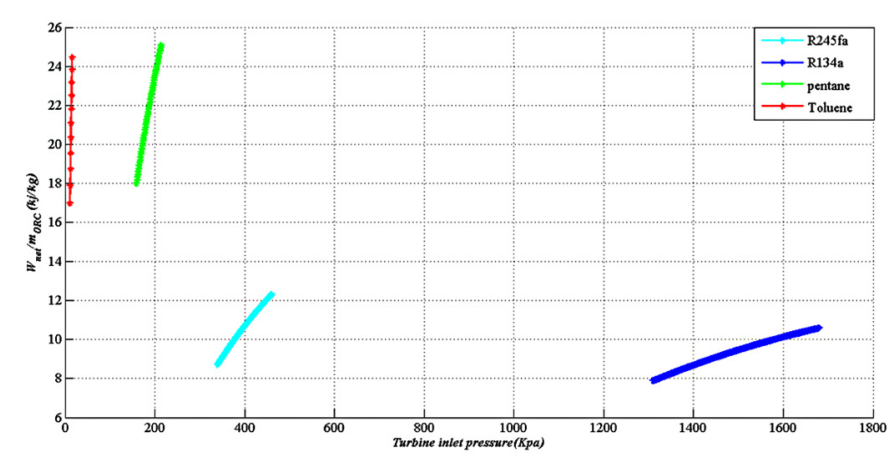

Fig. 12. Effect of turbine inlet pressure on the specific work of the ORC.

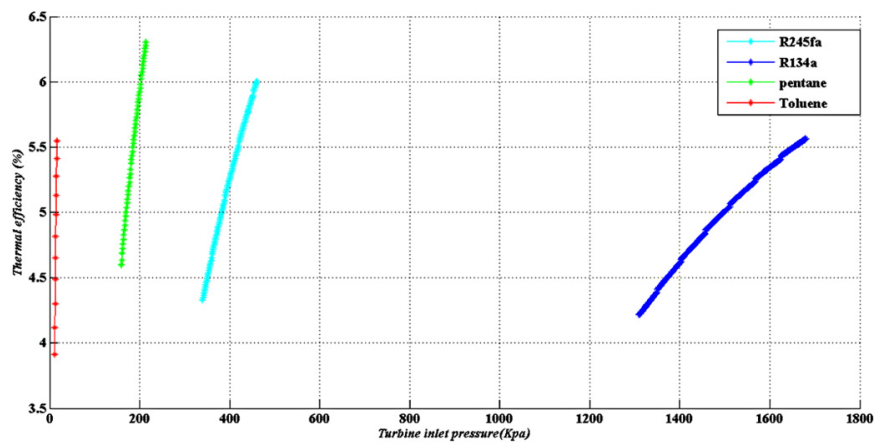

Fig. 13. Effect of turbine inlet pressure on the thermal efficiency of the ORC.

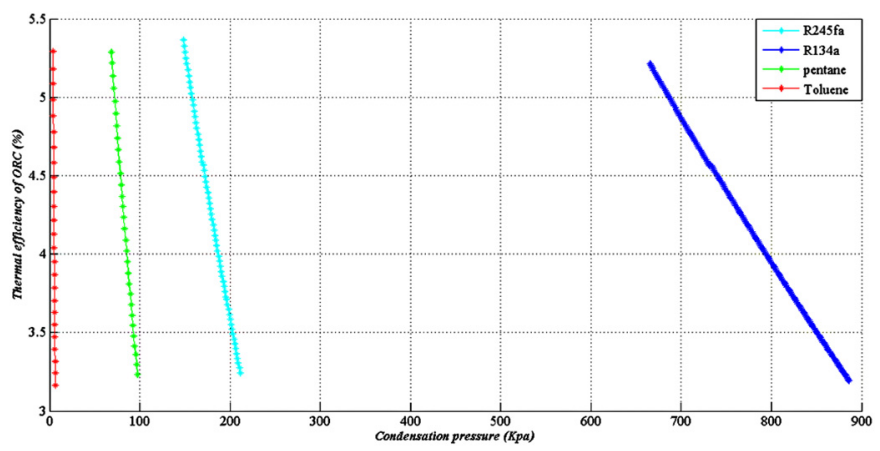

Fig. 14. Effect of condensation pressure on the thermal efficiency of the ORC.

According to Figures 14 and 15 lowering the condensation pressure will improve the thermal efficiency and increase the net output work. But this will lead to a lower condensation temperature of the system and there will be a need for a cooling water lower than ambient temperature which is not desirable. So the condensation pressures were fixed according to Table 2 to have the condensation temperature of $30^{\circ} \mathrm{C}$ to be cooled by water at ambient temperature.

\subsection{Exergy analysis results}

As can be seen in Figure 16, when the sun is shining during the day, a great amount of the input exergy is destructed in the collector (92 percent of the input exergy

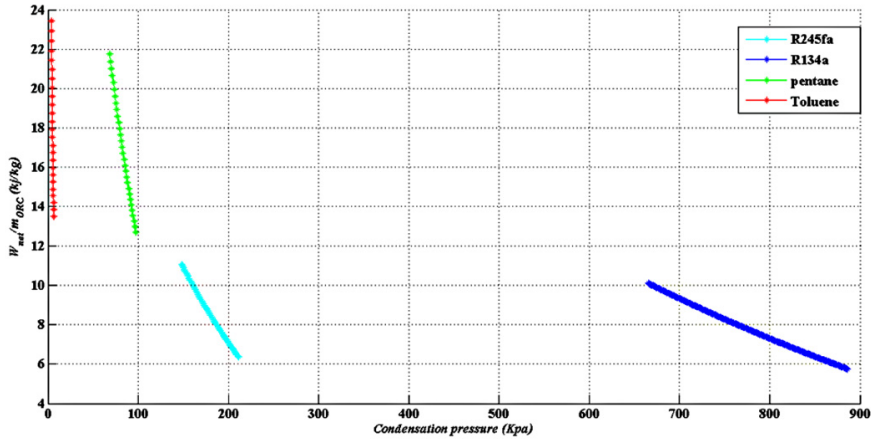

Fig. 15. Effect of condensation pressure on the specific work of the ORC.

of the sun). This is not a weird finding as we used a flat plate collector in the system to collect the exergy of the sun and there is not any focusing device to focus the sun's rays on the working fluid and most of the exergy of the sun is lost. Also, based on the detailed exergetic performance analysis of flat plate solar collectors presented by Farahat et al. [39] the exergy destruction seems quite reasonable. However, as the sun's rays are free source of energy the system is still promising. The overall exergy balance of the system is shown in Figure 16. There are three sources of input exergy into the system including sun's rays, auxiliary heater and accumulated exergy in the storage among which the sun's rays are the main and the most among them. During the sunshine a portion of input exergy from the sun is accumulated in the storage tank. This exergy is released during the night when the sun is not shining and acts as the exergy input to the system. Therefore, storage tank has a crucial role in providing stable heat source to the system. In times when storage tank is not capable of meeting the demand, the auxiliary heater starts by adding extra exergy to the system. The next important source of exergy destruction in the system is Vapor-Generator (6.89\% of input exergy). The main reason of this is due to the large temperature difference in the heat exchangers. As the turbine inlet temperature remains constant during the day to provide constant power during the day, the exergy destruction in the system is higher during higher radiation. Figure 17 shows the exergy flow diagram during a time when there is no useful gain for the collector and system uses the storage tank and the auxiliary heater to meet the demand. As can be seen in Figure 17, the tank releases heat to the system and auxiliary heater provide $15 \%$ of the total input exergy to the system to provides constant power of $1.54 \mathrm{~kW}$ electricity during all the day.

Table 4 shows the thermodynamic properties at each state at an hour during the day according to Figure 16. At this hour the sun shines and there is no need of auxiliary heater. Also the detailed exergetic parameters are listed in Table 4. As can be seen from the table, most of the sun's input exergy is lost in the collector and a small part of it $(7.53 \%)$ is given to the system as the useful input exergy. Storage tank also plays an important role in exergy destruction (78.37\%). But, a big part of it (68\%) is accumulated in the tank and is released to the system 
M. Ashouri et al.: Mechanics \& Industry 18, 217 (2017)

Table 4. Thermodynamic properties of the stations for solar ORC system.

\begin{tabular}{|c|c|c|c|c|c|c|}
\hline State & Fluid type & $\dot{m}\left(\mathrm{~kg} \cdot \mathrm{s}^{-1}\right)$ & $P(\mathrm{kPa})$ & $T(\mathrm{~K})$ & $h\left(\mathrm{~kJ} \cdot \mathrm{kg}^{-1}\right)$ & $e x\left(\mathrm{~kJ} \mathrm{~kg}^{-1}\right)$ \\
\hline 1 & R245fa & 0.18 & 177 & 303.03 & 238.94 & 3.56 \\
\hline 2 & R245fa & 0.18 & 340 & 303.16 & 239.11 & 3.64 \\
\hline 3 & $\mathrm{R} 245 \mathrm{fa}$ & 0.18 & 340 & 315.32 & 255.54 & 4.54 \\
\hline 4 & $\mathrm{R} 245 \mathrm{fa}$ & 0.18 & 340 & 322.75 & 265.74 & 5.37 \\
\hline 5 & $\mathrm{R} 245 \mathrm{fa}$ & 0.18 & 340 & 322.75 & 440.64 & 21.41 \\
\hline 6 & R245fa & 0.18 & 340 & 338.15 & 456.65 & 23.21 \\
\hline 7 & R245fa & 0.18 & 177 & 325.32 & 447.93 & 11.11 \\
\hline 8 & R245fa & 0.18 & 177 & 308.34 & 431.50 & 9.88 \\
\hline 9 & $\mathrm{R} 245 \mathrm{fa}$ & 0.18 & 177 & 303.03 & 426.34 & 9.67 \\
\hline $\mathrm{s}_{1}$ & water & 0.80 & 101.325 & 60.98 & 204.26 & 10.96 \\
\hline $\mathrm{s}_{2}$ & water & 0.80 & 101.325 & 71.76 & 240.41 & 17.13 \\
\hline $\mathrm{s}_{2^{\prime}}$ & water & 0.80 & 101.325 & 71.76 & 240.41 & 17.13 \\
\hline$c_{1}$ & water & 2.40 & 101.325 & 71.76 & 721.23 & 41.23 \\
\hline $\mathrm{c}_{2}$ & water & 2.40 & 101.325 & 85.38 & 858.32 & 64.04 \\
\hline $\mathrm{cw}_{1}$ & water & 1.50 & 101.325 & 20 & 84.01 & 0 \\
\hline $\mathrm{cw}_{2}$ & water & 1.50 & 101.325 & 25.36 & 106.43 & 0.20 \\
\hline $\mathrm{cw}_{3}$ & water & 1.50 & 101.325 & 25.51 & 107.05 & 0.21 \\
\hline
\end{tabular}
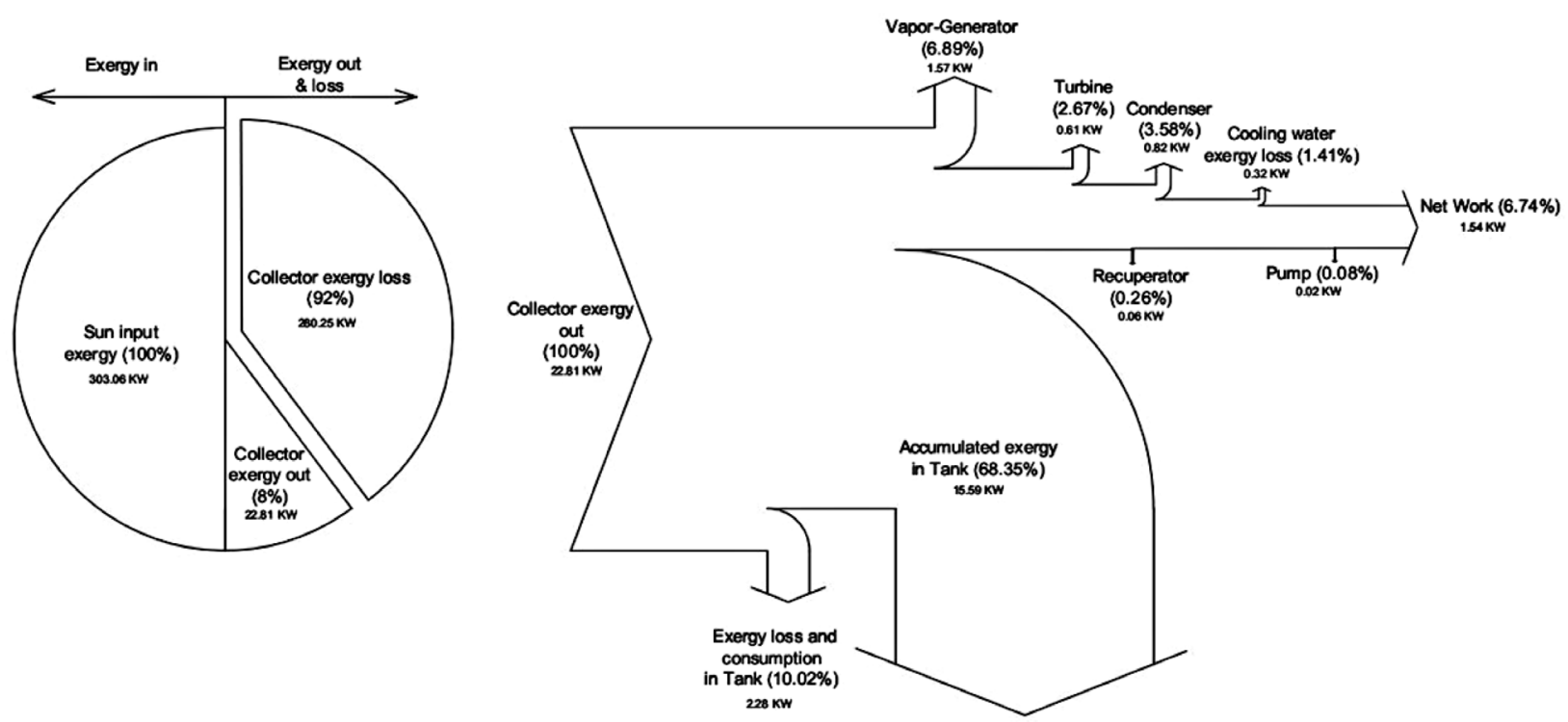

Fig. 16. Exergy flow diagram for the solar ORC system at an hour during the day and their corresponding fuel depletion ratios (percentages are based on input exergy).

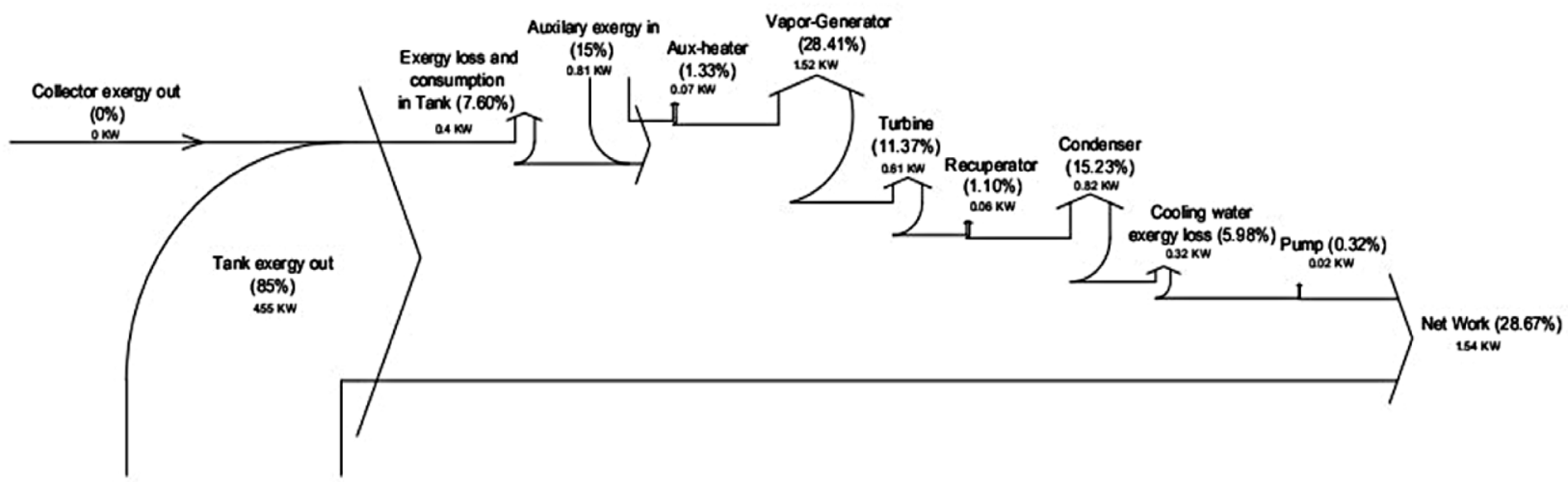

Fig. 17. Exergy flow diagram for the solar ORC system at an hour during discharging the storage tank and their corresponding fuel depletion ratios (percentages of input exergies are based on total input exergy to the system). 


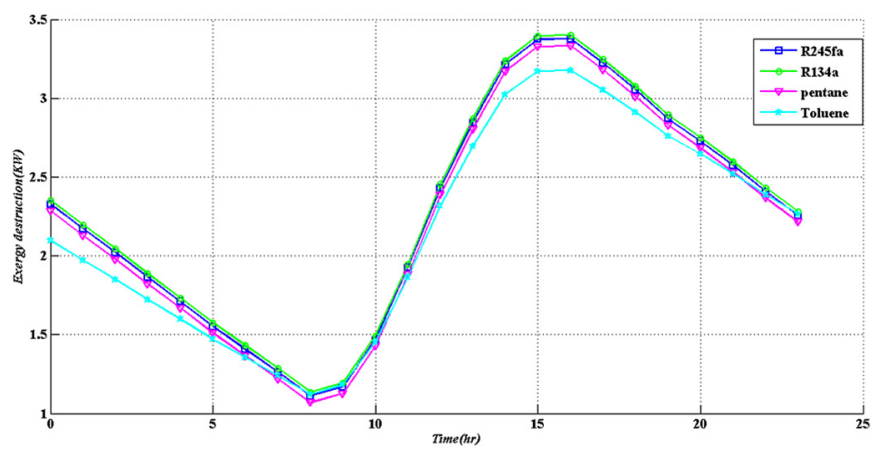

Fig. 18. Variation of vapor generator exergy destruction during the day for different working fluids.

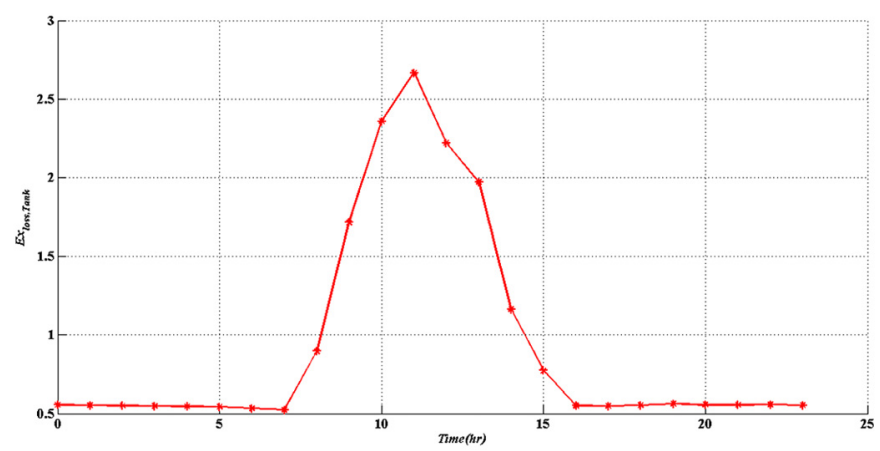

Fig. 19. Exergy loss of storage tank during the day under constant load.

during the night, thus cannot be considered loss for the overall system. Also, a better insulation material could help to reduce exergy losses to the ambient. Vapor generator is another source of exergy destruction (6.9\%) which is mainly due to temperature difference between incoming water $\left(\right.$ state $\left._{2^{\prime}}\right)$ and steam (state 6 ) which could be improved by lowering the pinch point temperature and increasing the heat exchanger surface area. Irreversibility ratios in Table 4 show that the collector has the highest destruction ratio of total destruction (92.94\%) followed by storage tank.

Figure 18 shows the vapor generator exergy destruction during the day under constant load for the four investigated working fluids. Also, the turbine inlet temperature is set to constant throughout the day to prevent thermal shock to turbine blades. As can be seen, the exergy destruction goes to the highest at about 15:00. The reason is the high temperature difference in heat exchangers during these hours. The destruction is at its lowest at about 8:00 where the temperatures of working fluids and storage tank are close to each other. Toluene and R134a have the lowest and highest exergy destruction, respectively, during sunshine.

Figure 19 shows the variation of exergy loss in the storage tank. Due to the direct relation between the tank temperature and exergy loss (see Eq. (43)), the tank loss increases with the tank temperature and decreases as the tank temperature falls.

The cumulative exergy destruction of the storage tank and the ORC versus turbine inlet temperature are shown

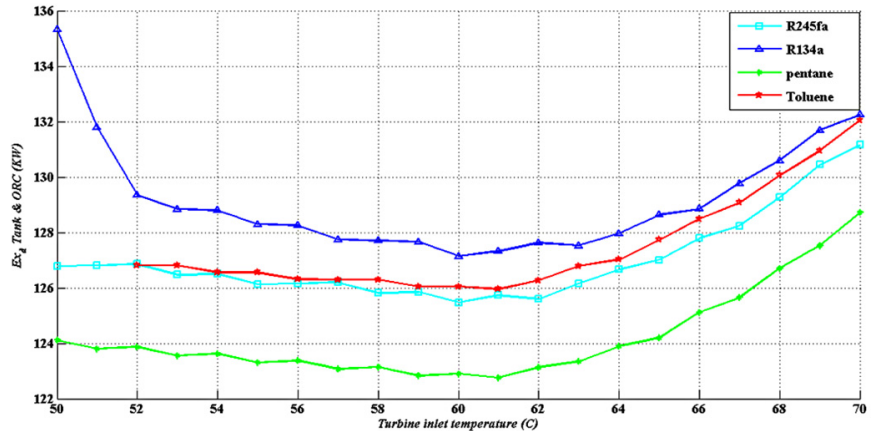

Fig. 20. Variation of total exergy destruction of storage Tank and ORC against turbine inlet temperature for different working fluids during the day.

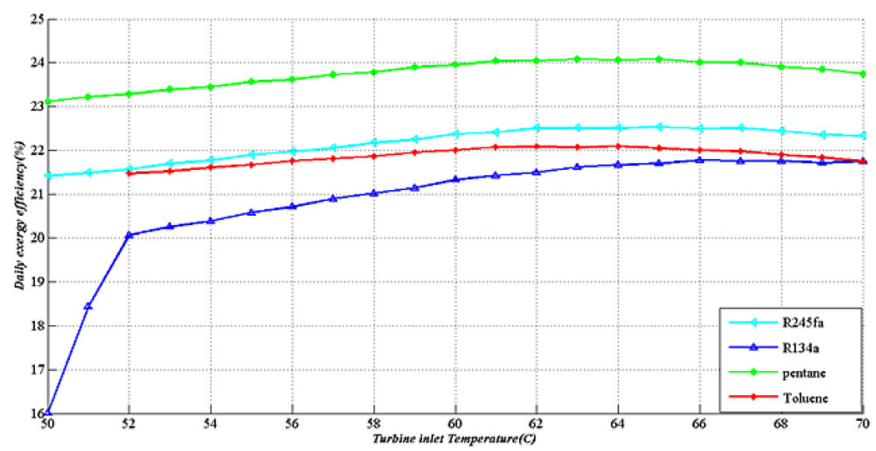

Fig. 21. Variation of turbine inlet temperature against useful daily exergetic efficiency of the system for different fluids.

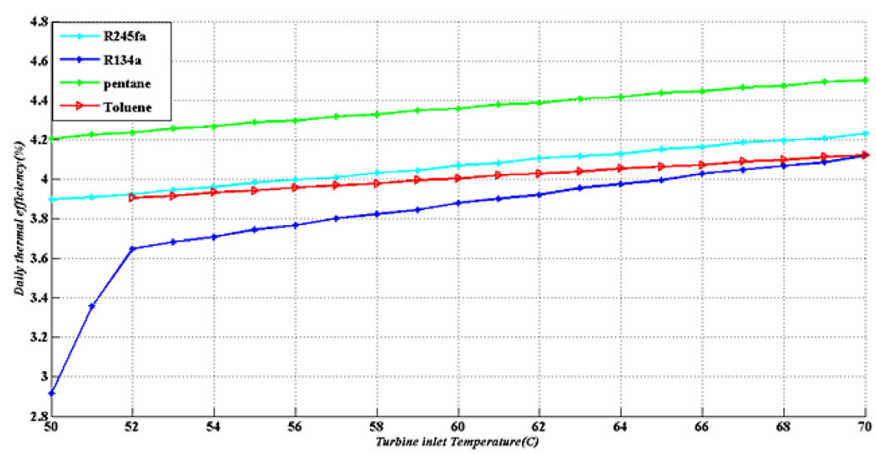

Fig. 22. Variation of turbine inlet temperature against daily energetic efficiency of the system for different fluids.

in Figure 20. The figure shows that as the temperature of the turbine hovers around $60{ }^{\circ} \mathrm{C}$, the destruction reaches to its minimum rate. The main reason to this behavior is that the temperature difference in the vapor generator becomes minimum at these temperatures.

Figures 21-23 show the effect of turbine inlet temperature on the performance of system on the condition that other parameters remain constant. As can be seen in Figure 21, the exergy efficiency for the system goes up with turbine inlet temperature at first and then falls. The reason is that by rising the temperature, a higher output power is achieved but this leads to a higher load demand of the ORC system. At temperatures more than $65{ }^{\circ} \mathrm{C}$ the load demand is higher compared to output work and 


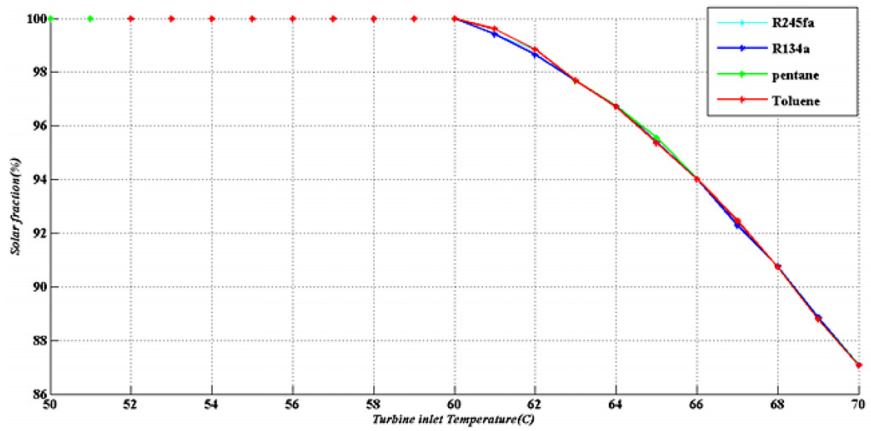

Fig. 23. Variation of turbine inlet temperature versus solar fraction for different working fluids.

Table 5. Detailed exergy parameters for R245fa at an hour during the day.

\begin{tabular}{ccccc}
\hline Components & $E x_{\mathrm{d}, \mathrm{j}}$ & $Y_{\mathrm{D}, \mathrm{j}}$ & $Y_{\mathrm{D}}^{*}$ & $\eta_{\mathrm{ex}}(\%)$ \\
\hline Collectors & 280.2508 & 0.9247 & 0.9294 & 7.53 \\
Storage Tank $^{*}$ & 17.8762 & 0.7837 & 0.8401 & 89.98 \\
Auxiliary heater & 0 & 0 & 0 & - \\
Vapor generator & 1.5733 & 0.0690 & 0.0739 & 68.11 \\
Turbine & 0.6097 & 0.0267 & 0.0287 & 72.02 \\
Recuperator & 0.0591 & 0.0026 & 0.0028 & 73.21 \\
Condenser & 1.1440 & 0.0502 & 0.0538 & 28.19 \\
Feed pump & 0.0170 & 0.0007 & 0.0008 & 46.32 \\
\hline
\end{tabular}

*Summation of exergy loss and accumulation in the tank (see Fig. 16).

more exergy is released from thermal storage tank resulting the exergy efficiency to fall. This trend is in agreement with exergy destruction rate in Figure 22. Although the destruction of the total system is the lowest at $60{ }^{\circ} \mathrm{C}$ according to Figure 18, the maximum exergy efficiency occurs at $65{ }^{\circ} \mathrm{C}$ because the exergy out from the storage tank is lower and causes the overall system to have the maximum exergy efficiency at $65^{\circ} \mathrm{C}$. Figure 22 shows the thermal efficiency of the overall system against turbine inlet temperature. As opposed to exergy efficiency, there is an increasing trend in the thermal efficiency with temperature. Therefore, from an exergy point of view, the highest turbine inlet temperature is not a good choice for the best performance of the system. Pentane has the best energetic and exergetic efficiency but it must work within higher pressure than toluene (see Table 1). R134a has the minimum efficiency and works under higher pressures (Table 1).

Figure 23 shows the variation of turbine inlet temperature on the solar fraction. As can be seen, the increase in inlet temperature leads to lower solar fraction as the load increases. Working fluids have the $S F$ equal to 1 for turbine inlet temperatures less than $60{ }^{\circ} \mathrm{C}$ but at the cost of lower output power. This shows that the system can work continuously without auxiliary heater. For all working fluids the solar fraction is more than $85^{\circ} \mathrm{C}$ and this shows a great contribution of the sun in the overall system. The pentane and R245fa have the highest daily exergetic efficiency but have approximately the same solar fraction.

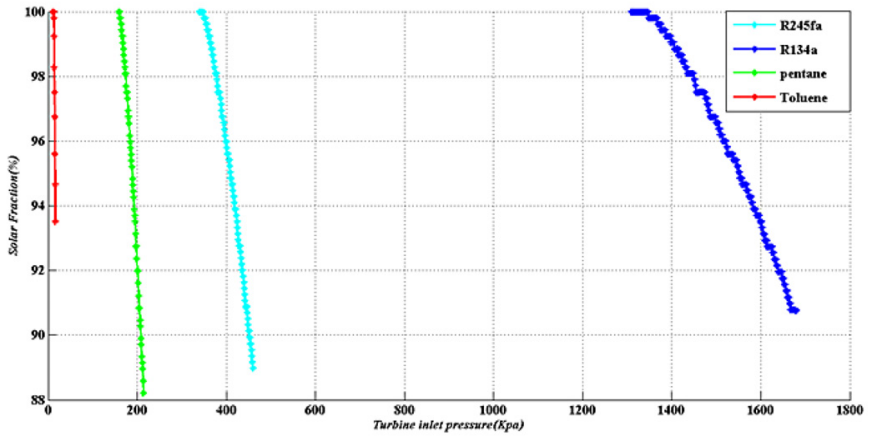

Fig. 24. Effect of turbine inlet pressure on the solar fraction.

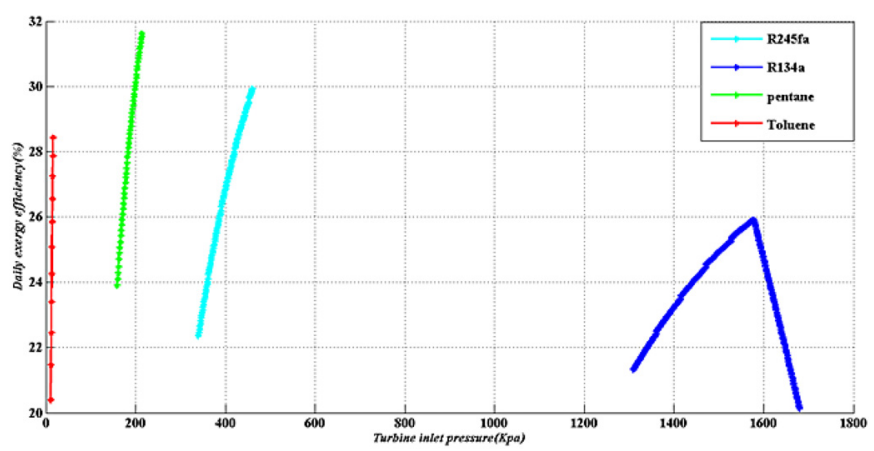

Fig. 25. Effect of turbine inlet pressure on the daily exergy efficiency.

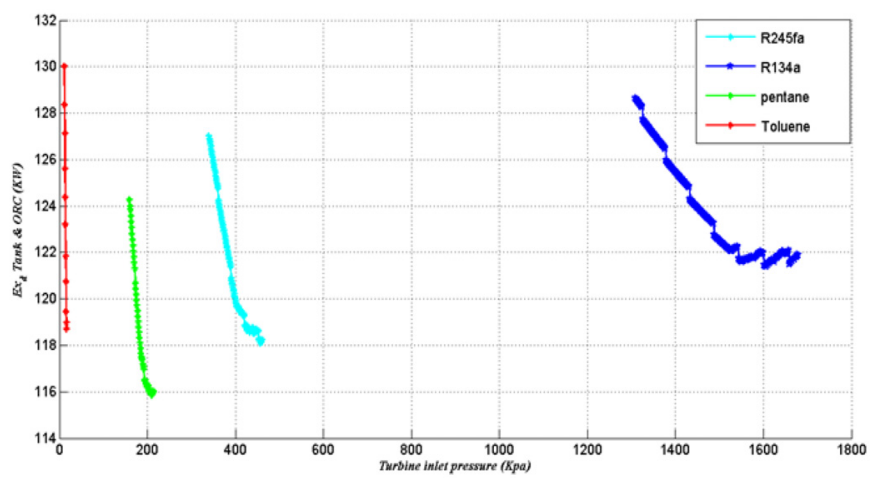

Fig. 26. Variation of total exergy destruction of storage Tank and ORC against turbine inlet pressure for different working fluids during the whole day.

Figure 24 shows the variation of turbine inlet pressure on the solar fraction at a constant temperature of $60{ }^{\circ} \mathrm{C}$ in which the solar fraction is one for all working fluids (see Fig. 23). As turbine inlet pressure increases leading to a higher load, the solar fraction decreases and the system uses more auxiliary heater.

Figures 25-27 show the effect of turbine inlet pressure on the daily exergy efficiency, exergy destruction of tank and ORC and energy efficiency of the system. As can be seen, for R134a, at first, increasing the inlet pressure causes more output power and increases the efficiency but gradually as the auxiliary heater adds exergy to the system, the efficiency falls. Therefore, there is an optimum pressure for the system to gain the highest exergy efficiency. Other fluids show a rising trend in efficiency at the cost of lower solar fraction. 


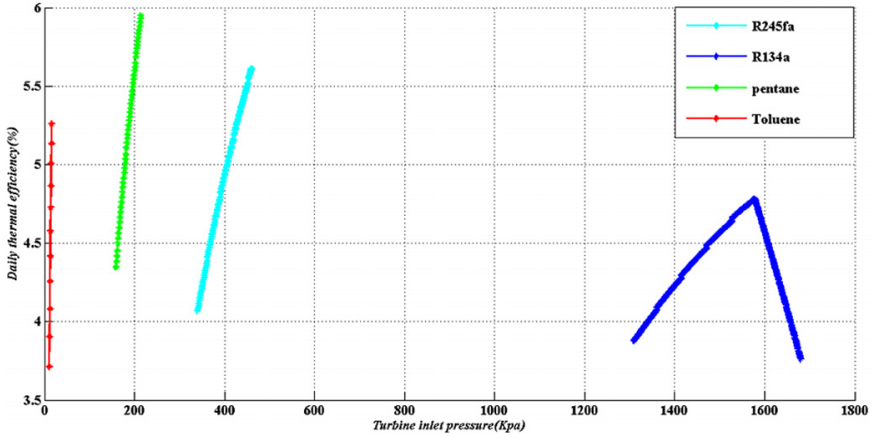

Fig. 27. Effect of turbine inlet pressure on the daily thermal efficiency.

\section{Conclusion}

In this study, a regenerative organic Rankine cycle coupled with a flat plate solar collector was analyzed energetically and exergetically. A fully mixed unpressurized water storage tank was used to provide stable power throughout the day. Exergy analysis gives a better understanding of the system to find the sources of exergy destruction. Daily exergy and energy efficiencies were introduced as the ratio of summation of the output work to useful exergy and input energy to the system during the day, respectively. Findings show that there is an optimum turbine inlet temperature based on daily exergy efficiency of the system. There is a significant need for a careful design of the flat plate collectors as most of the sun exergy in lost in the collectors (about 90\%). Four working fluids were examined as working fluids of the ORC. Pentane has the best exergetic performance under the same load followed by R245fa, toluene and R134a. Also, toluene has the best suitability compared to R245fa and R134a due to low operating pressure and nearly the same efficiencies. There is a slight improvement in the thermal efficiency of the system with increasing the turbine inlet temperature but for low cost applications lowering the turbine inlet temperature will not have a considerable effect on the thermal efficiency.

\section{References}

[1] Y. Dai, J. Wang, L. Gao, Parametric optimization and comparative study of organic Rankine cycle (ORC) for low grade waste heat recovery, Energy Convers. Manag. (2009) 576-582

[2] X.D. Wang, L. Zhao, J.L. Wang, W.Z. Zhang, X.Z. Zhao, W. Wu, Performance evaluation of a low-temperature solar Rankine cycle system utilizing R245fa, Solar Energy 84 (2010) 353-364

[3] T. Guo, H.X. Wang, S.J. Jhang, Selection of working fluids for a novel low-temperature geothermally powered ORC based cogeneration system, Energy Convers. Management. (2011) 946-952

[4] H. Chen, D.Y. Goswami, E. Stefanakos, A review of thermodynamic cycles and working fluids for the conversion of low-grade heat, Renew. Sust. Energy Rev. 14 (2010) 3059-3067
[5] B.F. Tchanche, Gr. Lambrinos, A. Frangoudakis, G. Papadakis, Low-grade heat conversion into power using organic Rankine cycles a review of various applications, Renew. Sustain. Energy Rev. 15 (2011) 3963-3979

[6] J. Li, G. Pei, J. Ji, Optimization of low temperature solar thermal electric generation with Organic Rankine Cycle in different areas, Appl. Energy 87 (2010) 3355-3365

[7] G. Pei, J. Li, J. Ji, Analysis of low temperature solar thermal electric generation using regenerative Organic Rankine Cycle, Appl. Thermal Energy 30 (2010) 998-1004

[8] S. Quoilin, M. Orosz, H. Hemond, V. Lemort, Performance and design optimization of a low-cost solar organic Rankine cycle for remote power generation, Solar Energy 85 (2011) 955-966

[9] R. Rayegan, YX. Tao, A procedure to select working fluids for Solar Organic Rankine Cycles (ORCs), Renew. Energy 36 (2011) 659-670

[10] J.L. Wang, L. Zhao, X.D. Wang, A comparative study of pure and zeotropic mixtures in low-temperature solar Rankine cycle. Appl. Energy. 87 (2010) 3366-3373

[11] Y.L. He, D.H. Mei, W.Q. Tao, W.W. Yang, H.L. Liu, Simulation of the parabolic trough solar energy generation system with Organic Rankine Cycle, Appl. Energy. 97 (2012) 630-641

[12] A.M. Delgado-Torres, L. García-Rodríguez. Analysis and optimization of the low temperature solar organic Rankine cycle (ORC), Energy Convers. Manag. 51 (2010) $2846-2856$

[13] A.M. Delgado-Torres, L. García-Rodríguez, Preliminary assessment of solar organic Rankine cycles for driving a desalination system. Desalination. 216 (2007) 252-275

[14] A.M. Delgado-Torres, L. García-Rodríguez, Double cascade organic Rankine cycle for solar-driven reverse osmosis desalination, Desalination 216 (2007) 306-313

[15] G. Kosmadakis, D. Manolakos, G. Papadakis, Parametric theoretical study of a two-stage solar organic Rankine cycle for RO desalination, Renew. Energy. 35 (2010) 989-996

[16] G. Kosmadakis, D. Manolakos, S. Kyritsis, G. Papadakis, Economic assessment of a two-stage solar organic Rankine cycle for reverse osmosis desalination, Renew. Energy 34 (2009) 1579-1586

[17] C. Li, G. Kosmadakis, D. Manolakos, E. Stefanakos, G. Papadakis, D.Y. Goswami, Performance investigation of concentrating solar collectors coupled with a transcritical organic Rankine cycle for power and seawater desalination cogeneration, Desalination. 318 (2013) 107-117

[18] A.S. Nafey, M.A. Sharaf, Combined solar organic Rankine cycle with reverse osmosis desalination process: energy, exergy, and cost evaluations, Renew. Energy 35 (2010) $2571-2580$

[19] A.S. Nafey, M.A. Sharaf, L. García-Rodríguez, Thermoeconomic analysis of a combined solar organic Rankine cycle-reverse osmosis desalination process with different energy recovery configurations, Desalination 261 (2010) $138-147$

[20] B. Peñate, L. García-Rodríguez, Seawater reverse osmosis desalination driven by a solar Organic Rankine Cycle: design and technology assessment for medium capacity range, Desalination 284 (2012) 86-91

[21] J.C. Bruno, J. López-Villada, E. Letelier, S. Romera, A. Coronas, Modelling and optimisation of solar organic 
Rankine cycle engines for reverse osmosis d esalination, Appl. Thermal Eng. 28 (2008) 2212-2226

[22] B.F. Tchanche, G.R. Lambrinos, A. Frangoudakis, G. Papadakis. Exergy analysis of micro-organic Rankine power cycles for a small scale solar driven reverse osmosis desalination system, Appl. Energy 87 (2010) 1295-1306

[23] M. Wang, J.F. Wang, Y.Z. Zhao, P. Zhao, Y.P. Dai. Thermodynamic analysis and optimization of a solardriven regenerative organic Rankine cycle (ORC) based on flat-plate solar collectors, Appl. Thermal Energy 50 (2013) 816-825

[24] Wang Jiangfeng, Zhequan Yan, Pan Zhao, Yiping Dai. Off-design performance analysis of a solar-powered organic Rankine cycle, Energy Convers. Manage. 80 (2014) $150-157$

[25] Jiangfeng Wang, Zhequan Yan, Enmin Zhou, Yiping Dai, Parametric analysis and optimization of a Kalina cycle driven by solar energy, Appl. Thermal Eng. 50 (2013) 408-415

[26] Pouria Ahmadi, Ibrahim Dincer, Marc A. Rosen, Energy and exergy analyses of hydrogen production via solarboosted ocean thermal energy conversion and PEM electrolysis., Int. J. Hydrogen Energy 38 (2013) 1795-1805

[27] Fahad A. Al-Sulaiman Exergy analysis of parabolic trough solar collectors integrated with combined steam and organic Rankine cycles, Energy Conver. Manage. 77 (2014) 441-449

[28] A.C. Mcmahan, Design Optimization of Organic Rankine Cycle Solar-Thermal Powerplants, MSc Thesis, 2006

[29] Renewable energy organization of IRAN (SANA), Database for solar irradiation, http://www.suna.org. ir/en/home
[30] J.A. Duffie, W.A. Beckman. Solar engineering of thermal processes, 3rd edition, J. Willey \& Sons, New York 2006

[31] S. Sukhatme, Solar Energy-principles of Thermal Collection and Storage, Tata McGraw-Hill Publishing Company Limited, India, 1984

[32] Ibrahim Dincer, Marc A. Rosen. Exergy, Energy, Environment and sustainable development, 1st ed. Elsevier Science, 2007

[33] V. Siva Reddy, S.C. Kaushik, K.R. Ranjan, S.K. Tyagi, State-of-the-art of solar thermal power plants - A review. Renew, Sust. Energy Rev. 27 (2013) 258-273

[34] NIST Standard Reference Database 23, NIST Thermodynamic and Transport Properties of Refrigerants and Refrigerant Mixtures REFROP, Version 8.0 (2007)

[35] Petela R. Exergy analysis of the solar cylindricalparabolic cooker, Sol Energy 79 (2005) 221-233

[36] Bejan A, Tsatsaronis G, Moran M. Thermal design and optimization, JohnWiley and Sons, Inc., 1996

[37] Ameri M, Ahmadi P. The study of ambient temperature effects on exergy losses of a heat recovery steam generator. Proceeding of the International Conference on power engineering. Hang Zhou, China, 2007, pp. 55-61

[38] Pouria Ahmadi, Ibrahim Dincer, Marc A. Rosen, Exergy, exergoeconomic and environmental analyses and evolutionary algorithm based multi-objective optimization of combined cycle power plants, Energy 36 (2011) 5886-5898

[39] S. Farahat, F. Sarhaddi, H. Ajam, Exergetic optimization of flat plate solar collectors, Renew, Energy 34 (2009) $1169-1174$ 